Article

\title{
Precise Synthesis and Thermoresponsive Property of Poly(ethyl glycidyl ether) and Its Block and Statistic Copolymers with Poly(glycidol)
}

\author{
Tingyu He ${ }^{1}$, Yanqiu Wang ${ }^{1}$, Atsushi Narumi ${ }^{2} \mathbb{D}$, Liang $\mathrm{Xu}{ }^{1}$, Shin-ichiro Sato ${ }^{3}$, Xiande Shen ${ }^{1,4, *}$ \\ and Toyoji Kakuchi 1,3,4,*
}

check for

updates

Citation: He, T.; Wang, Y.; Narumi,

A.; Xu, L.; Sato, S.-i.; Shen, X.;

Kakuchi, T. Precise Synthesis and

Thermoresponsive Property of

Poly(ethyl glycidyl ether) and Its

Block and Statistic Copolymers with

Poly(glycidol). Polymers 2021, 13 ,

3873. https://doi.org/10.3390/

polym13223873

Academic Editor: Asterios

(Stergios) Pispas

Received: 17 October 2021

Accepted: 3 November 2021

Published: 9 November 202

Publisher's Note: MDPI stays neutral with regard to jurisdictional claims in published maps and institutional affiliations.

Copyright: (C) 2021 by the authors Licensee MDPI, Basel, Switzerland. This article is an open access article distributed under the terms and conditions of the Creative Commons Attribution (CC BY) license (https:// creativecommons.org/licenses/by/ $4.0 /)$
1 Research Center for Polymer Materials, School of Materials Science and Engineering, Changchun University of Science and Technology, Jilin 130022, China; 13019166435@163.com (T.H.); yqwang@cust.edu.cn (Y.W.); m13069984921@163.com (L.X.)

2 Graduate School of Organic Materials Science, Yamagata University, Yamagata 992-8510, Japan; narumi@yz.yamagata-u.ac.jp

3 Division of Applied Chemistry, Faculty of Engineering, Hokkaido University, Hokkaido 060-8628, Japan; s-sato@eng.hokudai.ac.jp

4 Chongqing Research Institute, Changchun University of Science and Technology, Chongqing 401135, China

* Correspondence: shenxiande@cust.edu.cn (X.S.); kakuchi@eng.hokudai.ac.jp (T.K.)

Abstract: In this paper, we describe a comprehensive study of the thermoresponsive properties of statistic copolymers and multiblock copolymers synthesized by poly(glycidol)s (PG) and poly(ethyl glycidyl ether) (PEGE) with different copolymerization methods. These copolymers were first synthesized by ring-opening polymerization (ROP), which was initiated by tert-butylbenzyl alcohol ( $t \mathrm{BBA})$ and 1-tert-butyl-4,4,4-tris(dimethylamino)-2,2-bis[tris(dimethylamino)phosphoranylidenamino]-2 $\Lambda^{5}$, $4 \Lambda^{5}$-catenadi(phosphazene) $\left(t-\mathrm{Bu}_{-} \mathrm{P}_{4}\right)$ as the catalyst, and then the inherent protective groups were removed to obtain the copolymers without any specific chain end groups. The thermoresponsive property of the statistic copolymer $\mathrm{PG}_{x}$-stat-PEGE $y$ was compared with the diblock copolymer $\mathrm{PG}_{x}$ $b$ PEGE $_{y}$, and the triblock copolymers were compared with the pentablock copolymers. Among them, PG-stat-PEGE, PG- $b$-PEGE- $b$-PG- $b$-PEGE- $b$-PG, and PEGE- $b$-PG- $b$-PEGE- $b$-PG- $b$-PEGE, and even the specific ratio of PEGE- $b$-PG- $b$-PEGE, exhibited LCST-type phase transitions in water, which were characterized by cloud point $\left(T_{\mathrm{cp}}\right)$. Although the ratio of $\mathrm{x}$ to $\mathrm{y}$ affected the value of the $T_{\mathrm{cp}}$ of $\mathrm{PG}_{\mathrm{x}}$-stat-PEGE $\mathrm{y}$, we found that the disorder of the copolymer has a decisive effect on the phasetransition behavior. The phase-transition behaviors of PG- $b$-PEGE, part of PEGE- $b$-PG- $b$-PEGE, and PG- $b$-PEGE- $b$-PG copolymers in water present a two-stage phase transition, that is, firstly LCST-type and then the upper critical solution temperature (UCST)-like phase transition. In addition, we have extended the research on the thermoresponsive properties of EGE homopolymers without specific $\alpha$-chain ends.

Keywords: statistic copolymers; block copolymers; thermoresponsive polymers; LCST

\section{Introduction}

Aqueous solutions of some polymers show reversible phase-transition behavior, such as white turbidity when heated above the lower critical solution temperature (LCST) and dissolving again to clear when cooled below the LCST [1-3]. Such polymers include poly ( $N$-substituted acrylamide)), poly ( $N$-substituted methacrylamide), polyethers, and methyl cellulose [4-8]. On the other hand, sulfobetaine polymers, which are bipolar polymers, are known as polymers showing the upper critical solution temperature (UCST) after phase separation at low temperatures [9-11]. These polymers have been actively studied not only from the purely basic interest in clarifying phase-transition phenomena of aqueous solutions of polymers but also from the application aspect as intelligent polymers. The 
phase separation of poly ( $N$-isopropylacrylamide) (PNIPAM) has been analyzed from various aspects using methods such as turbidimetry, calorimetry, nuclear magnetic resonance, fluorescence, light scattering, and neutron scattering [12-14]. It has been clarified by these studies that the macroscopic phase-separation phenomenon of PNIPAM is accompanied by the shrinkage phenomenon of polymer chains, called coil-globule transition $[15,16]$. That is to say, under LCST, polymer chains are dissolved by strong interactions between amide groups and water and take a statistic coil state [17]. However, when the hydrogen bond between amide groups and water is unstable due to the rise in water temperature and dehydration of the hydrophobic part occurs, polymer chains shrink to a globule state. In addition, it is important to clarify how the hydration state of each part of a polymer is changed by hydrophobic interaction. Since the infrared spectrum is sensitive to intermolecular interaction, a series of research was conducted by analyzing the hydration state of polymers using this method $[15,18]$.

The clear-turbid phase transition occurred before and after cloud point temperature $\left(T_{\mathrm{cp}}\right)$ [19-23]. The polymer hydration is thus wrapped by water molecules and dissolves when the temperature is lower than $T_{\mathrm{cp}}$. The dehydration reaction is accompanied by the entanglement of polymer chains when the temperature is higher than $T_{\mathrm{cp}}$, and its hydrophilicity, hydrophobicity, volume, micelle structure, etc., will change significantly as the temperature changes [24-26]. In recent years, poly(ethylene glycol) (PEG) [27], poly( $N$-isopropylacrylamide) (PNIPAM) [15], poly(poly-2-dimethylaminoethyl methacrylate) (PDMAEMA) [28], poly(N-vinyl caprolactam) (PNVCL) [29], poly(diethyl vinylphosphonate) (PDEVP) [30], and poly(oligoethylene glycol methacrylate) (POEGMA) [31], etc., have been widely studied.

To make the thermoresponsive polymer have a better application value, it is usually required that the polymer be equipped with an adjustable transition temperature in a wider temperature range. As has been established, linear thermoresponsive glycerol-polyethers can be excellent candidates due to their good biocompatibility and adjustability [32,33]. Poly(glycidyl ether)s, based on glycidyl methyl ether (GME) [34], ethoxyethyl glycidyl ether (EEGE) [35], and ethyl glycidyl ether (EGE) [35,36] exhibit thermoresponsive properties and undergo a coil-to-globule phase transition in water. Aoki et al. [35] detected that the phase transition temperature of these homopolymers is located at $14.6^{\circ} \mathrm{C}$ for PEGE, $40.0^{\circ} \mathrm{C}$ for PEEGE, and $57.7^{\circ} \mathrm{C}$ for PGME and thus outside the physiologically relevant temperature range. To expand the scope of application of the polyglycerols, these water-soluble polyglycerol derivatives have received much attention due to their inherent biocompatible properties. Ogura et al. [37] synthesized the new amphiphilic diblock copolymers, which were named poly(ethyl glycidyl ether)-block-poly(ethylene oxide) (PEGE-b-PEO), and further aggregated the core shell into micelles at $40{ }^{\circ} \mathrm{C}$, which is probably due to triggering by dehydration of the PEO chain segment. Interestingly, P(GME-co-EGE) copolymers with different GME/EGE ratios that have a cloud-point range from $10{ }^{\circ} \mathrm{C}$ to $60^{\circ} \mathrm{C}$ prepared by Reinicke et al. [38] show similar behavior to those in the works of Weinhart et al. [39]. The poly(GME)-stat.-Co-(EGE) has an LCST at approximately $30^{\circ} \mathrm{C}$, with a monomer feed ratio of 1:3 (GME/EGE).

Hence, statistic copolymerization and block copolymerization are the general approaches used to adjust the ratio of two monomers to control the solubility of the polymer and select one or two temperature-sensitive monomers in order to design the $T_{\mathrm{cp}}$ of polymeric aggregates [40,41]. Previously, we expanded our precision BnGE-polymerization system to the synthesis of the "pristine" PG, as a glycerol-backbone polymeric intermediate, which can be post-modified to acquire a new thermoresponsive property of polymer $\mathrm{PG}_{n^{-}}$ $\mathrm{EO}_{m} \mathrm{R}^{\prime}$ [42]. Starting from here, we decided to design PG into the new thermoresponsiveproperty material by the incorporation of the more hydrophobic EGE comonomer using block and statistic copolymerization methods. In recent years, the development of structural versatility and the use of PG derivatives in biomedical applications have advanced by leaps and bounds [43]. The PG structure is very unique, with one hydroxyl group per 
repeated unit applicable, and the LCST can be induced by hydrophobic modification of the hydroxyl groups and provide a blueprint to utilize them in biomedical applications.

In this study, we designed the copolymerization system of BnGE and EGE to extend to the synthesis of block copolymers and statistic copolymers without any specific end groups, that is, the multiple copolymers using PG as the hydrophilic chain segment and PEGE as the temperature-sensitive segment, as shown in Scheme 1. This study reports: (1) the living controlled ROP was catalyzed by $t$-Bu- $P_{4}$ using $t B B A$ as initiator through the statistic and block copolymerization methods and then deprotected to obtain $\mathrm{PG}_{\mathrm{X}}{ }^{-}$ stat-PEGE $\mathrm{y}_{\mathrm{y}}$ and $\mathrm{PG}_{\mathrm{x}}-b-\mathrm{PEGE}_{\mathrm{y}}$, and the thermoresponsive properties of these copolymers with different $x / y$ ratios were comprehensively studied; (2) the synthesis of multiblock copolymers composed of PG and PEGE chains, $\mathrm{PG}_{15}-b-\mathrm{PEGE}_{70}-b-\mathrm{PG}_{15}, \mathrm{PG}_{35}-b-\mathrm{PEGE}_{30}-$ $b-\mathrm{PG}_{35}, \mathrm{PEGE}_{15}-b-\mathrm{PG}_{70}-b-\mathrm{PEGE}_{15}, \mathrm{PEGE}_{35}-b-\mathrm{PG}_{30}-b-\mathrm{PEGE}_{35}, \mathrm{PEGE}_{20}-b-\mathrm{PG}_{20}-b-\mathrm{PEGE}_{20}-b-$ $\mathrm{PG}_{20}-b-\mathrm{PEGE}_{20}$, and $\mathrm{PG}_{20}-b-\mathrm{PEGE}_{20}-b-\mathrm{PG}_{20}-b-\mathrm{PEGE}_{20}-b-\mathrm{PG}_{20}$, to explore the effect of the disorder to the copolymers on the thermoresponsive property; (3) we not only designed and synthesized the homopolymer PEGE without specific $\alpha$-chain ends but also used dynamic light-scattering (DLS) measurement to explore the thermoresponsive properties of polymers in aqueous solutions.
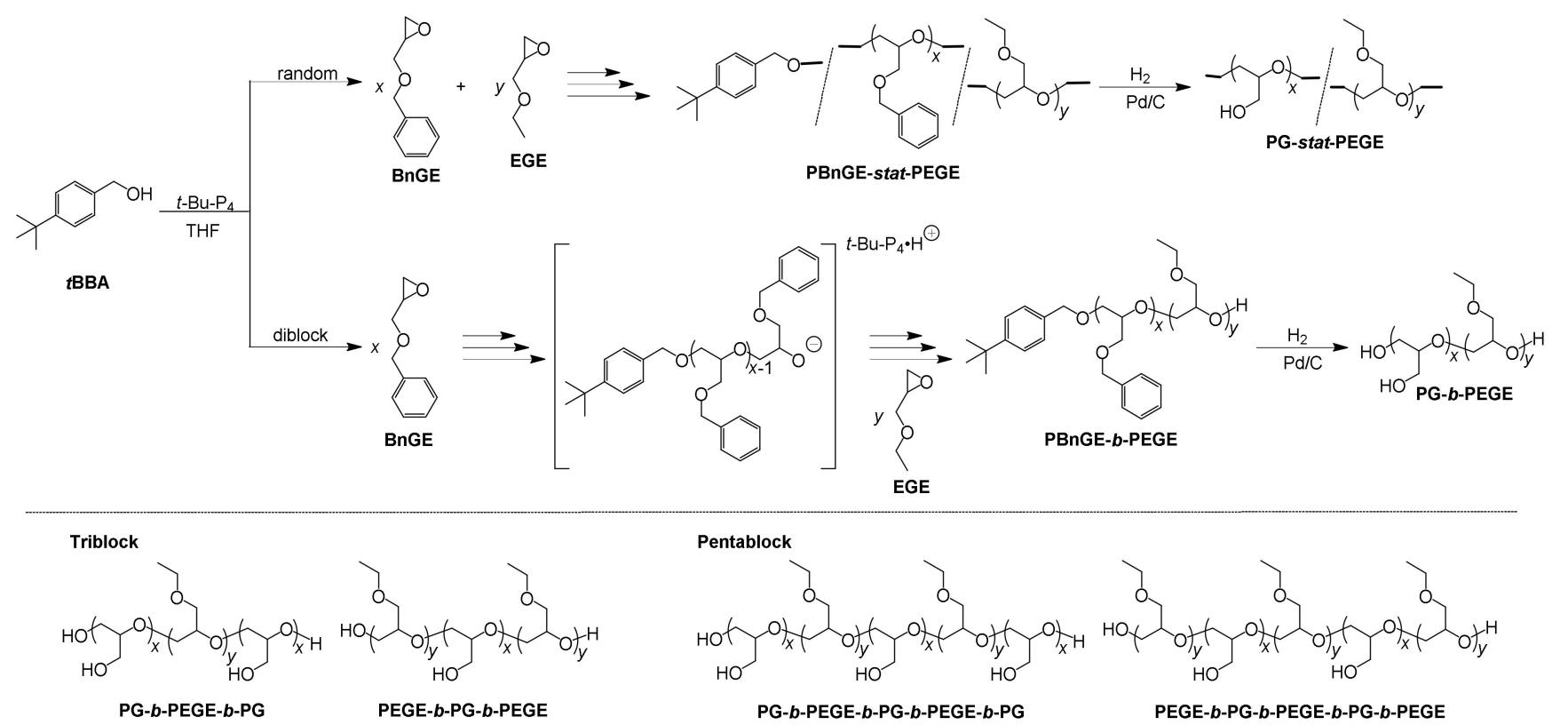

Scheme 1. Synthesis of statistic and block copolymers (PG-stat-PEGE and PG- $b$-PEGE, PG- $b$-PEGE- $b$-PG, PEGE- $b$-PG- $b$ PEGE, PG- $b$-PEGE- $b$-PG- $b$-PEGE- $b$-PG, and PEGE- $b$-PG- $b$-PEGE- $b$-PG- $b$-PEGE, respectively).

\section{Materials and Methods}

\subsection{Materials}

Dichloromethane, extra dry, with molecular sieves (water $<50 \mathrm{ppm}$ ) was purchased from Energy Chemicals Co., Inc. (Anhui, China) and was used as received. Dry toluene (purity, $>99.5 \%$, water content, $<0.001 \%$ ) for polymerization was purchased from Energy Chemicals Co., Ltd. and distilled in an Ar atmosphere over sodium benzophenone. Benzyl glycidyl ether (BnGE), 4-tert-butyl-benzyl alcohol (tBBA), and glycidyl ethyl ether (EGE) were purchased from Tokyo Kasei Kogyo Co., Ltd. (TCI, Tokyo, Japan) and distilled over $\mathrm{CaH}_{2}$ two times prior to use. 1-tert-Butyl-4,4,4-tris(dimethylamino)-2,2-bis[tris (dimethylamino) phosphoranylid enamino]- $2 \Lambda^{5}, 4 \Lambda^{5}$-catenadi(phosphazene) $\left(t-\mathrm{Bu}-\mathrm{P}_{4} ; 0.8 \mathrm{M}\right.$ solution in $n$-hexane) was purchased from Sigma-Aldrich (St. Louis, MO, USA). Palladium on charcoal (Pd/C, 10\%) was purchased from Energy Chemicals Co., Ltd. and was used as received. 


\subsection{Synthesis of PBnGE-stat-PEGE}

A typical procedure for the statistic copolymerization of BnGE and EGE is described as follows: To a solution of $t$ BBA $(6.57 \mathrm{mg}, 40 \mu \mathrm{mol})$ in $1.41 \mathrm{~mL}$ dry toluene, $0.05 \mathrm{~mL}$ of $t$-Bu- $\mathrm{P}_{4}$ (40 $\mu \mathrm{mol}$ as $0.8 \mathrm{M}$ solution in $n$-hexane), EGE $(0.20 \mathrm{~g}, 2 \mathrm{mmol})$, and BnGE $(0.33 \mathrm{~g}, 2 \mathrm{mmol})$ were added, in this order. The color of the solution changed from light yellow to dark yellow, indicating that the polymerization was successfully initiated. The polymerization was then quenched by adding a small amount of benzoic acid mixture to the polymerization solution. Aliquots were removed from the polymerization mixture to determine the conversion of BnGE and EGE by ${ }^{1} \mathrm{H}$ NMR measurements. The obtained polymer was purified through neutralized aluminum oxide to obtain $\mathrm{PBnGE}_{50}$-stat-PEGE 50 as a colorless and viscous liquid. Yield, $92.9 \% ; M_{n, N M R}, 13.5 \mathrm{~kg} \mathrm{~mol}^{-1} ; M_{\mathrm{w}} / M_{\mathrm{n}}, 1.07$.

\subsection{Synthesis of PG-stat-PEGE}

A typical deprotection procedure is described as follows: Palladium on carbon (10\% $\mathrm{Pd} / \mathrm{C} ; 100 \mathrm{mg})$ was added to a solution of $\mathrm{PBnGE}_{50}$-stat-PEGE $50(100 \mathrm{mg} ; 7.41 \mu \mathrm{mol})$ in a mixture of methanol and $\mathrm{CH}_{2} \mathrm{Cl}_{2}(1 / 1, v / v ; 10.00 \mathrm{~mL})$, and the whole mixture was stirred under a hydrogen atmosphere ( $3-5 \mathrm{MPa}$ ) for $24 \mathrm{~h}$. After removing the $\mathrm{Pd} / \mathrm{C}$ catalyst by filtration using celite, the solution was evaporated to obtain PG $_{50}$-stat-PEGE 50 as a colorless and viscous liquid. Yield, $93.4 \% ; M_{\mathrm{w}, \mathrm{MALS}}, 8.8 \mathrm{~kg} \mathrm{~mol}^{-1} ; M_{\mathrm{w}} / M_{\mathrm{n}}, 1.10$.

\subsection{Synthesis of PBnGE-b-PEGE}

A typical procedure for the diblock copolymerization of BnGE and EGE is described as follows: To a solution of $t$ BBA $(6.57 \mathrm{mg}, 40 \mu \mathrm{mol})$ in $1.41 \mathrm{~mL}$ dry toluene, $0.05 \mathrm{~mL}$ of $t$-Bu- $\mathrm{P}_{4}(40 \mu \mathrm{mol}$ as $0.8 \mathrm{M}$ solution in $n$-hexane) and BnGE ( $0.33 \mathrm{~g}, 2 \mathrm{mmol})$ were added, in this order. The color of the solution changed from light yellow to dark yellow, indicating that the polymerization was successfully initiated. After completion of BnGE polymerization ( $20 \mathrm{~h}$, determined by the conversion of BnGE by ${ }^{1} \mathrm{H}$ NMR measurements), EGE $(0.20 \mathrm{~g}, 2 \mathrm{mmol})$ was further added to the polymerization mixture to continue the block copolymerization for $20 \mathrm{~h}$. The polymerization was then quenched by adding a small amount of benzoic acid mixture to the polymerization solution. Aliquots were removed from the polymerization mixture to determine the conversion of BnGE and EGE by ${ }^{1} \mathrm{H}$ NMR measurements. The obtained polymer was purified through neutralized aluminum oxide to obtain $\mathrm{PBnGE}_{50}-b-\mathrm{PEGE}_{50}$ as a colorless and viscous liquid. Yield, 93.6\%; $M_{n, \mathrm{NMR}}$, $13.5 \mathrm{~kg} \mathrm{~mol}^{-1} ; M_{\mathrm{w}} / M_{\mathrm{n}}, 1.05$.

\subsection{Synthesis of PG-b-PEGE}

A typical deprotection procedure is described as follows. Palladium on carbon (10\% $\mathrm{Pd} / \mathrm{C} ; 100 \mathrm{mg})$ was added to a solution of $\mathrm{PBnGE}_{50}-b-\mathrm{PEGE}_{50}(100 \mathrm{mg} ; 7.41 \mu \mathrm{mol})$ in a mixture of methanol and $\mathrm{CH}_{2} \mathrm{Cl}_{2}(1 / 1, v / v ; 10.00 \mathrm{~mL})$, and the whole mixture was stirred under a hydrogen atmosphere ( $3-5 \mathrm{MPa}$ ) for $24 \mathrm{~h}$. After removing the $\mathrm{Pd} / \mathrm{C}$ catalyst by filtration using celite, the solution was evaporated to obtain $\mathrm{PG}_{50}-b-\mathrm{PEGE}_{50}$ as a colorless and viscous liquid. Yield, $90.5 \% ; M_{\mathrm{w}, \mathrm{MALS}}, 8.8 \mathrm{~kg} \mathrm{~mol}^{-1} ; M_{\mathrm{w}} / M_{\mathrm{n}}, 1.13$.

\subsection{Characterization}

The ${ }^{1} \mathrm{H}$ and ${ }^{13} \mathrm{C}$ NMR spectra were recorded using a Bruker AVANCE III HD 500 (Bruker, Billerica, MA, USA) test in Changchun, China.

The polymerization solution was prepared in a MIKROUNA glove box (Changchun, China) equipped with a gas-purification system (molecular sieves and copper catalyst) and a dry argon atmosphere $\left(\mathrm{H}_{2} \mathrm{O}, \mathrm{O}_{2}<1 \mathrm{ppm}\right)$. The moisture and oxygen contents in the glove box were monitored by a MK-XTR-100 and a MK-OX-SEN-1, respectively.

The number of average molecular weights $\left(M_{n} s\right)$ and molecular weight distributions $\left(M_{\mathrm{W}} / M_{\mathrm{n}} \mathrm{s}\right)$ of the polymers were measured by size exclusion chromatography (SEC) using an Agilent high-performance liquid chromatography (1260 Infinity II) system (Agilent, Santa Clara, CA, USA) in THF or $\mathrm{H}_{2} \mathrm{O}$ in the presence of $0.05 \% \mathrm{NaN}_{3}$ at a flow rate 
of $1.0 \mathrm{~mL} \mathrm{~min}^{-1}$. The weight average molecular weight $\left(M_{\mathrm{w}, \mathrm{MALS}}\right)$ was determined by the SEC equipped with a multiangle laser light-scattering (MALS) instrument (Wyatt Technology, DAWN 8 HELEOS $^{\circledR}$ ) (Santa Barbara, CA, USA) in DMF in the presence of $0.01 \mathrm{M} \mathrm{LiCl}$ at a flow rate of $1.0 \mathrm{~mL} \mathrm{~min}^{-1}$. SEC(THF): Agilent PLgel $(7.5 \times 300 \mathrm{~mm}$, average bead size: $10 \mu \mathrm{m}$, exclusion limit: $\left.2 \times 10^{6} \mathrm{~g} \mathrm{~mol}^{-1}\right)$, PLgel $(7.5 \times 300 \mathrm{~mm}$, average bead size: $10 \mu \mathrm{m}$, exclusion limit: $4 \times 10^{8} \mathrm{~g} \mathrm{~mol}^{-1}$ ), columns. SEC(DMF): Agilent Polar Gel-M $\left(7.5 \times 300 \mathrm{~mm}\right.$, average bead size: $5 \mu \mathrm{m}$, exclusion limit: $\left.2 \times 10^{4} \mathrm{~g} \mathrm{~mol}^{-1}\right)$, Polar Gel-M $\left(7.5 \times 300 \mathrm{~mm}\right.$, average bead size: $5 \mu \mathrm{m}$, exclusion limit: $\left.4 \times 10^{6} \mathrm{~g} \mathrm{~mol}^{-1}\right)$, columns.

The hydrodynamic diameter $\left(D_{\mathrm{h}} \mathrm{s}\right)$ of the obtained polymer was analyzed using a dynamic light-scattering (DLS) detector (Wyatt Technology, Dyna Pro Nanostar ${ }^{\circledR}$ ) test in Changchun, China.

The cloud-point measurements were performed based on the ultraviolet-visible (UVvis) spectra by passing through a 10-mm path-length cell using a Jasco V-770 spectrophotometer (Tokyo, CA, Japan) equipped with a temperature-controller (Jasco CTU-100) test in Changchun, China. The temperature was increased at the rate of $1^{\circ} \mathrm{C} \mathrm{min}-1$, and the transmittance change with temperature was recorded using a spectrophotometer at the wavelength of $500 \mathrm{~nm}$.

The matrix-assisted laser desorption/ionization time-of-flight mass spectrometry Bruker Autoflex III (MALDI-TOF MS) (Bruker, Billerica, MA, USA) measurements were performed using an Applied Biosystems Voyager-DE STR-H mass spectrometer with a 25-kV acceleration voltage test in Changchun, China. The positive ions were detected in reflector mode $(25 \mathrm{kV})$. A nitrogen laser $\left(337 \mathrm{~nm}, 3 \mathrm{~ns}\right.$ pulse width, $106-107 \mathrm{~W} \mathrm{~cm}^{-2}$ ) operating at $3 \mathrm{~Hz}$ was used to produce the laser desorption, and the 200 shots were summed. The spectra were externally calibrated using a sample prepared from narrow-dispersed polystyrene. Samples for the MALDI-TOF MS were prepared by mixing the polymer $\left(1.5 \mathrm{mg} \mathrm{mL}^{-1}, 10 \mu \mathrm{L}\right.$ ), the matrix (trans-3-indoleacrylic acid, $10 \mathrm{mg} \mathrm{mL}^{-1}, 90 \mu \mathrm{L}$ ), and the actionizing agent (sodium trifluoroacetate, $10 \mathrm{mg} \mathrm{mL}^{-1}, 10 \mu \mathrm{L}$ ) in THF.

\section{Results and Discussion}

\subsection{Synthesis of Statistic Copolymers and Block Copolymers}

For preliminary research, we studied a series of copolymers of BnGE and EGE obtained by statistic/block copolymerization methods, i.e., PBnGE-stat-PEGE, PBnGE- $b$-PEGE. In accordance with Scheme 1, PBnGE was first prepared by the $t$-Bu- $\mathrm{P}_{4}$-catalyzed anionic ROP of the monomer BnGE using 4-tert-butylbenzyl alcohol ( $t \mathrm{BBA}$ ) as the initiator, followed by EGE as the $\mathrm{M}_{2 \text { nd }}$ monomer for statistic/block copolymerization. Table 1 shows the list of the copolymerization results. Here, the total number with the ratio of monomers to initiator $\left(\left[\mathrm{M}_{1 \mathrm{st}}\right]_{0} /[\mathrm{tBBA}]\right)$ and $\left(\left[\mathrm{M}_{2 \mathrm{nd}}\right]_{0} /[\mathrm{BBA}]\right)$ in the two stages is controlled at 100 to produce the copolymers with different molecular weights. All polymerization reactions are carried out with the monomer conversion rate (conversion rate $>99.9 \%$ ) to produce the corresponding copolymers, which required molecular weight ranges from 10.8 to $15.6 \mathrm{~kg} \mathrm{~mol}^{-1}$. We prepared copolymers through the random copolymerization of BnGE with EGE, which are termed as, statistical copolymers. All of the size exclusion chromatography (SEC) traces of the PBnGE-stat-PEGE (Figure 1) showed a unimodal distribution, which demonstrated narrow dispersity $\left(M_{\mathrm{w}} / M_{\mathrm{n}}\right)$ values of no more than 1.1. Obviously, as the ratio of $[\mathrm{PBnGE}]_{0} /[t \mathrm{BBA}]_{0}$ increased and $[\mathrm{PEGE}]_{0} /[t \mathrm{BBA}]_{0}$ decreased, it shifted to the higher molecular-weight region. The synthesis of PBnGE-stat-PEGE was carried out under the conditions of $[\mathrm{PBnGE}]_{0} /[\mathrm{EGE}]_{0}=10 / 90,20 / 80,30 / 70,40 / 60,50 / 50,60 / 40,70 / 30$, $80 / 20$, and 90/10 (entries 1-9). Similarly, the syntheses of PBnGE- $b$-PEGE were performed with $\left[\mathrm{M}_{1 \mathrm{st}}\right]_{0} /\left[\mathrm{M}_{2 \mathrm{nd}}\right]_{0}=10 / 90,20 / 80,30 / 70,40 / 60$ and 50/50 (runs 10-14), respectively. In addition, the SEC trace showed a symmetrical monomodal peak with the $M_{\mathrm{w}} / M_{\mathrm{n}}$ value of 1.05-1.08, which implied the absence of the side reactions like chain transfer during the block. 
Table 1. Synthesis of $\mathrm{PBnGE}_{\mathrm{x}}$-stat-PEGE $\mathrm{y}$ and $\mathrm{PBnGE}_{\mathrm{x}}-b-\mathrm{PEGE}_{\mathrm{y}}$ by statistic ROP of BnGE and EGE and block ROP of BnGE as the first monomer and EGE as the second monomer, respectively, using $t \mathrm{BBA}$ as the initiator and $t$-Bu- $\mathrm{P}_{4}$ as the catalyst ${ }^{a}$.

\begin{tabular}{|c|c|c|c|c|c|c|}
\hline Entry $^{b}$ & Code & {$[\mathrm{BnGE}]_{0} /[\mathrm{EGE}]_{0}$} & $\begin{array}{c}M_{\mathrm{n}, \mathrm{calcd}} \\
\left(\mathrm{kg} \mathrm{mol}^{-1}\right)^{c}\end{array}$ & $\begin{array}{c}M_{\mathrm{n}, \mathrm{NMR}} \\
\left(\mathrm{kg} \mathrm{mol}^{-1}\right)^{d}\end{array}$ & $M_{\mathrm{w}} / M_{\mathrm{n}}{ }^{e}$ & $\mathbf{x}, \mathbf{y}^{f}$ \\
\hline 1 & \multirow{9}{*}{$\mathrm{PBnGE}_{\mathrm{x}}$-stat-PEGE $\mathrm{y}$} & $10 / 90$ & 11.0 & 10.8 & 1.10 & 10,88 \\
\hline 2 & & $20 / 80$ & 11.6 & 11.5 & 1.09 & 20,79 \\
\hline 3 & & $30 / 70$ & 12.2 & 12.2 & 1.09 & 30,70 \\
\hline 4 & & $40 / 60$ & 12.9 & 12.9 & 1.08 & 40,60 \\
\hline 5 & & $50 / 50$ & 13.5 & 13.5 & 1.07 & 50,50 \\
\hline 6 & & $60 / 40$ & 14.1 & 14.1 & 1.08 & 60,40 \\
\hline 7 & & $70 / 30$ & 14.7 & 14.7 & 1.08 & 70,30 \\
\hline 8 & & $80 / 20$ & 15.3 & 15.0 & 1.10 & 78,20 \\
\hline 9 & & $90 / 10$ & 16.0 & 15.6 & 1.09 & 88,10 \\
\hline 10 & \multirow{5}{*}{$\mathrm{PBnGE}_{\mathrm{x}}-b-\mathrm{PEGE}_{\mathrm{y}}$} & $10 / 90$ & 11.0 & 10.8 & 1.08 & 10,88 \\
\hline 11 & & $20 / 80$ & 11.6 & 11.5 & 1.05 & 20,79 \\
\hline 12 & & $30 / 70$ & 12.2 & 12.2 & 1.04 & 30,70 \\
\hline 13 & & $40 / 60$ & 12.9 & 12.9 & 1.07 & 40,60 \\
\hline 14 & & $50 / 50$ & 13.5 & 13.5 & 1.05 & 50,50 \\
\hline
\end{tabular}

${ }^{a}$ solvent, toluene; Ar atmosphere; temperature, room temp.; [BnGE and EGE $]_{0}, 2.0 \mathrm{~mol} \mathrm{~L}^{-1}$; $[\mathrm{BBA}]_{0} /\left[t-\mathrm{Bu}-\mathrm{P}_{4}\right]_{0}, 1.0$; monomer conversions were determined by ${ }^{1} \mathrm{H}$ NMR in $\mathrm{CDCl}_{3} .{ }^{b}$ Entries 1-9, statistic copolymerization, polymerization time, $20 \mathrm{~h}$; entries 10-14, diblock copolymerizations, 1st and 2nd polymerization times, $20 \mathrm{~h}$ and $20 \mathrm{~h} ;{ }^{c} M_{n, \text { calcd }}=\left\{\left([\mathrm{BnGE}]_{0} /[t \mathrm{BBA}]_{0}\right) \times(\right.$ conv. of BnGE $\left.) \times(\mathrm{MW} \mathrm{of} \mathrm{BnGE})\right\}$ $+\left\{\left([\mathrm{EGE}]_{0} /[t \mathrm{BBA}]_{0}\right) \times(\right.$ conv. of EGE $) \times(\mathrm{MW}$ of EGE $\left.\left.)\right]\right\}+\{(\mathrm{MW}$ of $t \mathrm{BBA})\} .{ }^{d}$ Determined from ${ }^{1} \mathrm{H}$ NMR spectra in $\mathrm{CDCl}_{3} .{ }^{e}$ Determined by $^{d}$ SEC in THF using PS standards. ${ }^{f}$ Determined from the ${ }^{1} \mathrm{H}$ NMR spectra in $\mathrm{CDCl}_{3}$.

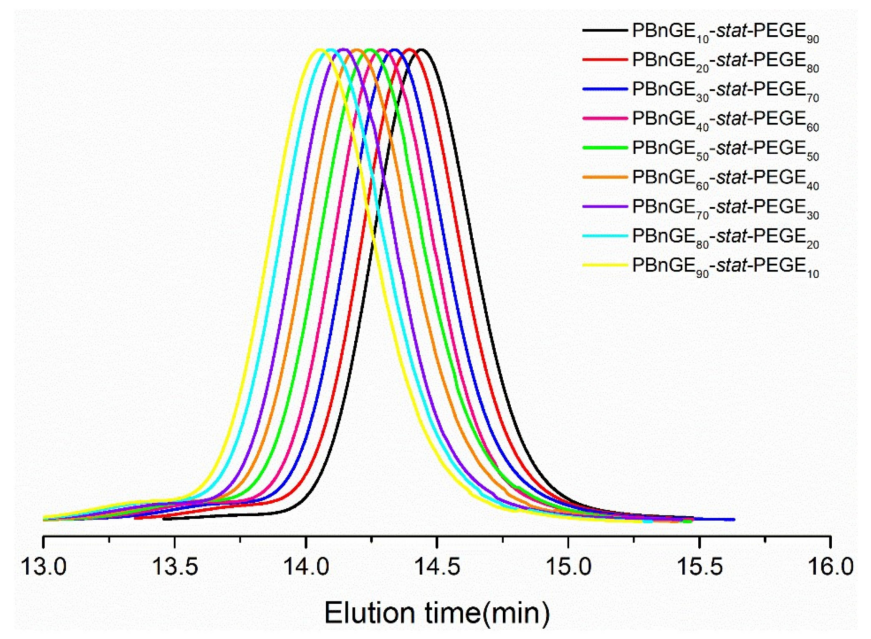

Figure 1. SEC trace of $\mathrm{PBnGE}_{\mathrm{x}}$-stat-PEGE $\mathrm{P}$ in THF.

As shown in Figure 2, the structures of $\mathrm{PBnGE}_{50}$-stat-PEGE 50 (entry 5, Table 1) were verified by the ${ }^{1} \mathrm{H}$ NMR and ${ }^{13} \mathrm{C}$ NMR spectra. The ${ }^{1} \mathrm{H}$ NMR test revealed the comonomer ratio of BnGE to EGE and proved the presence of $t \mathrm{BBA}$, which initiated the polymer. Comparing the integrals of the characteristic ethyl group $(f)$ peaks of BnGE at $4.45 \mathrm{ppm}$ and the characteristic methyl group $(k)$ peaks of EGE at $1.16 \mathrm{ppm}$ revealed results very consistent with the comonomer ratio, with the targeted 1 to 1 ratio. The characteristic allyl (e) peaks at $1.36 \mathrm{ppm}$, assigned to the tert-butyl group at the $\alpha$-chain end in PBnGE-stat-PEGE, confirmed that the presence of $t \mathrm{BBA}$ initiated the copolymerization. The peaks of the methylene protons $(a, c, g$, and $i)$ and the methine protons $(b$ and $h)$ in the polymer main chains at 3.38-3.74 ppm, as well as those assigned to the methylene group protons ( $j$ ) of EGE peak and the methylene proton (d) peaks of $t \mathrm{BBA}$, obviously verified the successful copolymerization of PBnGE-stat-PEGE. Combined NMR and SEC measurements revealed the final composition of the statistic copolymer as PBnGE-stat-PEGE. Technically, ${ }^{1} \mathrm{H}$ NMR measurements still provided reliable information on the average degree of polymerization of the units generated for BnGE and EGE polymerizations ( $x$ and $y$, respectively). Additionally, 
the ${ }^{1} \mathrm{H}$ NMR spectra can obtain the number average molecular weights $\left(M_{n, N M R s}\right)$ of the copolymer, which is consistent with the calculated molecular weight $\left(M_{n, \text { calcd }}\right)$ determined by the monomer conversion and even the $\left[\mathrm{M}_{1 \mathrm{st}}\right]_{0} /\left[\mathrm{M}_{2 \text { nd }}\right]_{0} /[\mathrm{ROH}]_{0}$ values. Representative examples are as follows: the $M_{n, \mathrm{NMR}}\left(M_{\mathrm{n}, \text { calcd }}\right)$ values are $10.8(11.0), 11.5$ (11.6), 12.2 (12.2), 12.9 (12.9), and 13.5 (13.5) $\mathrm{kg} \mathrm{mol}^{-1}$ of PBnGE-stat-PEGE (Table 1, entries 1-5). In summary, $\mathrm{PBnGE}_{10}$-stat-PEGE $90, \mathrm{PBnGE}_{20}$-stat-PEGE $80, \mathrm{PBnGE}_{30}$-stat-PEGE $70, \mathrm{PBnGE}_{40}$-stat-PEGE 60 , $\mathrm{PBnGE}_{50}$-stat-PEGE $50, \mathrm{PBnGE}_{60}$-stat-PEGE $40, \mathrm{PBnGE}_{70}$-stat-PEGE $30, \mathrm{PBnGE}_{80}$-stat-PEGE 20 , and $\mathrm{PBnGE}_{90}$-stat-PEGE 10 were synthesized, thus allowing debenzylation research in the next step.

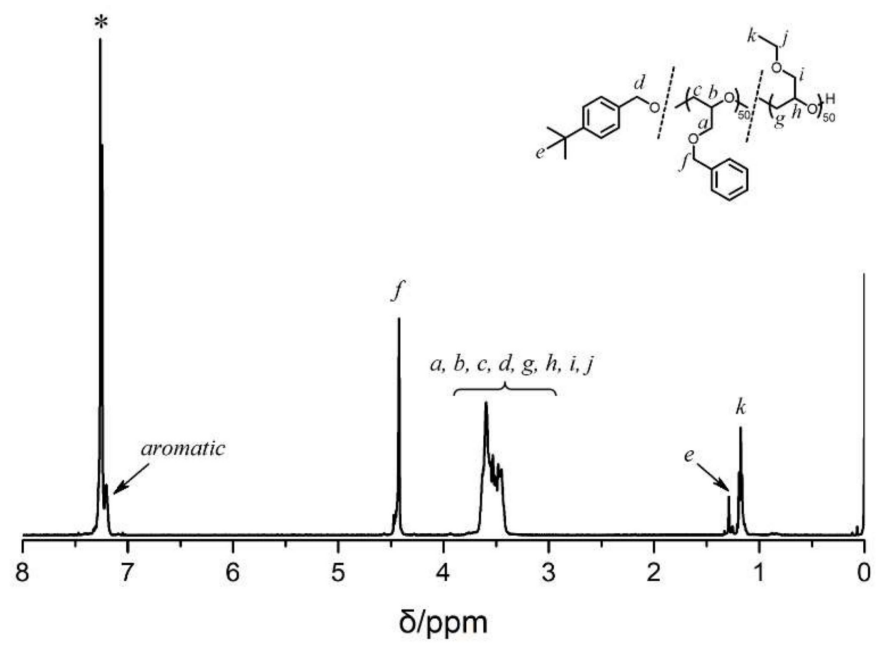

(a)

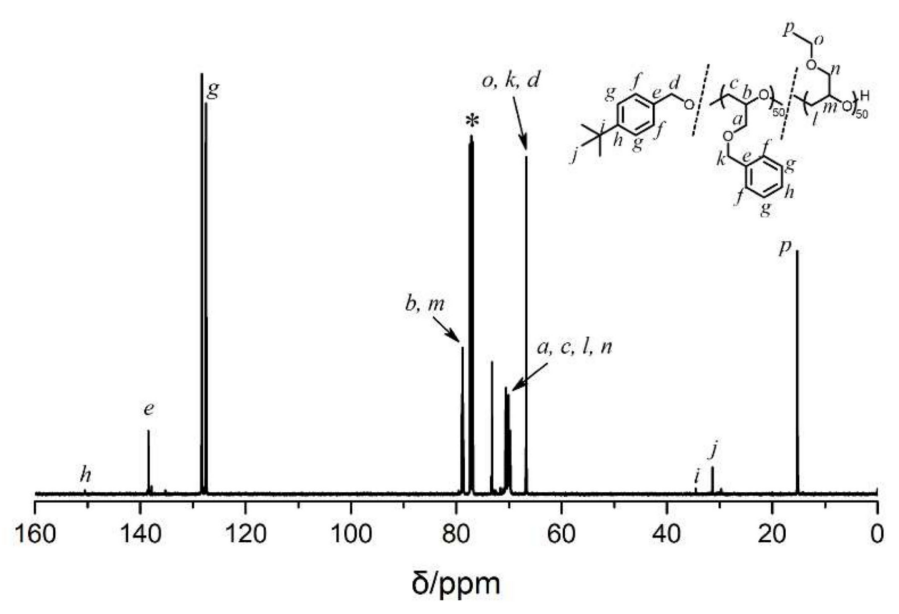

(b)

Figure 2. ${ }^{1} \mathrm{H}$ NMR (a) and ${ }^{13} \mathrm{C}$ NMR (b) spectra of $\mathrm{PBnGE}_{50}$-stat-PEGE 50 in $\mathrm{CDCl}_{3}$ (the symbol * refers to solvent peaks).

We aimed to investigate the thermoresponsive behaviors of the PG-b-PEGE consisting of PG and PEGE in order to gain insight into the effect of the monomer sequence. Thus, we conducted the sequential block copolymerization of PBnGE, followed by EGE, using the $t$-Bu- $\mathrm{P}_{4} / t \mathrm{BBA}$ system with $[\mathrm{BnGE}]_{0} /[\mathrm{EGE}]_{0} /[\mathrm{BBBA}]_{0}$ ratios of 10/90/1, 20/80/1, 30/70/1, $40 / 60 / 1$, and $50 / 50 / 1$ to afford a series of PBnGE $_{x}-b-$ PEGE $_{\mathrm{y}}$ with various $\mathrm{x}$ and $\mathrm{y}$ values (Scheme 1 and Table 1). As the first step of block copolymerization, $t-\mathrm{Bu}-\mathrm{P}_{4}$ with a $[\mathrm{BnGE}]_{0} /[\mathrm{tBBA}]_{0} /\left[t-\mathrm{Bu}-\mathrm{P}_{4}\right]_{0}$ ratio of 50/1/1 catalyzed ROP of BnGE for $20 \mathrm{~h} .{ }^{1} \mathrm{H}$ NMR and SEC analysis of aliquots of the polymer showed that the monomer conversion rate reached $99 \%$, and it was verified that active PBnGE oxyanions were formed, with an $M_{n, \text { NMR }}$ value of $8.3 \mathrm{~kg} \mathrm{~mol}^{-1}$ and $M_{\mathrm{W}} / M_{\mathrm{n}}$ of 1.04 . Then, the block copolymerization second stage was started by adding 50 equivalents of EGE relative to the $t$ BBA used for the first polymerization. While monitoring the polymerization by ${ }^{1} \mathrm{H} N \mathrm{NMR}$, the quantitative consumption of EGE after $24 \mathrm{~h}$ can be observed. What is more, the ${ }^{1} \mathrm{H}$ NMR and ${ }^{13} \mathrm{C}$ NMR of the obtained copolymer $\mathrm{PBnGE}_{50}-b-\mathrm{PEGE}_{50}$ can capture the proton signal and carbon atom signal corresponding to PBnGE and PEGE, with calculated $M_{\mathrm{w}} / M_{\mathrm{n}}$ and $M_{\mathrm{n}, \mathrm{NMR}}$ of 1.05 and $13.5 \mathrm{~kg} \mathrm{~mol}^{-1}$, respectively. As shown in Figure 3, the SEC trace of the final product, $\mathrm{PBnGE}_{50}-b-\mathrm{PEGE}_{50}$, has shifted to a higher molecular-weight region compared with the $\mathrm{PBnGE}_{50}$ obtained in the first stage of polymerization. It is not difficult to find that there is a small shoulder in the SEC curve in the higher molecular-weight region, but the $M_{\mathrm{w}} / M_{\mathrm{n}}$ value of 1.05 , including the shoulder, is still very narrow. The only shoulder showed in this trace is in the high molecular-weight region, which could be from the termination of the polymerization. These results confirmed the successful block copolymerization to produce $\mathrm{PBnGE}_{50}-b-\mathrm{PEGE}_{50}$ with a predictable molecular weight and narrower $M_{\mathrm{w}} / M_{\mathrm{n}}$. $\mathrm{PBnGE}_{10}-b$-PEGE $90, \mathrm{PBnGE}_{20}-b-\mathrm{PEGE}_{80}, \mathrm{PBnGE}_{30}-b-\mathrm{PEGE}_{70}$, and $\mathrm{PBnGE}_{40}-b-\mathrm{PEGE}_{60}$ were also successfully prepared in the same manner. In addition, we also prepared the triblock and pentablock polymerizations (Table S1 and Table S3, Supplementary Material). 


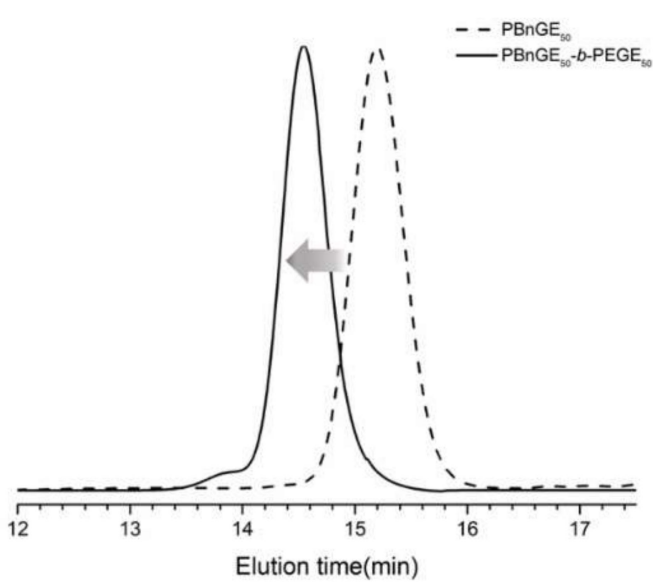

Figure 3. SEC traces of $\mathrm{PBnGE}_{50}-b-\mathrm{PEGE}_{50}$ in THF.

\subsection{Synthesis and Characterizations of PG-stat-PEGE and PG-b-PEGE}

In order to obtain the designed copolymers PG-stat-PEGE and PG- $b$-PEGE, we used $\mathrm{Pd} / \mathrm{C}$ as the catalyst to hydrogenate and crack a total of 14 samples of PBnGE-stat-PEGE and PBnGE- $b$-PEGE, and further removed the benzyl (Bn) group and 4-tert-butylbenzyl $(t \mathrm{BBn})$ in the PBnGE segment. The deprotection reaction was performed under a hydrogen atmosphere, and methanol $/ \mathrm{CH}_{2} \mathrm{Cl}_{2}$ (1:1) was used as a mixed solvent at room temperature. The ${ }^{1} \mathrm{H}$ NMR measurement was performed to further confirm the quantitative progress of each reaction, and then the samples were purified to obtain pure deprotected polymers in a viscous liquid state (entries 15-28 in Table 2). The SEC traces of the PG-stat-PEGE after the debenzylation reaction are monomodal peaks, as shown in Figure S1 (Supplementary Material), the $M_{\mathrm{w}} / M_{\mathrm{n}}$ values of which are summarized in Table 2, ranging from 1.10 to 1.15 , with a separation yield ranging from $85.3 \%$ to $93.5 \%$. More importantly, by analyzing the values of $M_{\mathrm{w}} / M_{\mathrm{n}}$ in Tables 1 and 2, it is concluded that the debenzylation reaction of the polymer did not lead to a significant broadening of the molecular-weight distribution.

As shown in Figure 4, for the ${ }^{1} \mathrm{H}$ NMR spectrum and the ${ }^{13} \mathrm{C}$ NMR spectrum of $\mathrm{PG}_{50}$ stat-PEGE 50 , PG as the main chain segment protons $(a, b$, and $c)$ appeared at $3.48-3.82 \mathrm{ppm}$, and the characteristic peaks of $\mathrm{Bn}$ and $t \mathrm{BBn}$ groups were not observed in the spectrum. However, the PG signals through the ${ }^{13} \mathrm{C}$ NMR spectrum can be confirmed again, which appeared at 62.0, 80.4, and $70.8 \mathrm{ppm}(a, b$, and $c$, respectively). It is worth noting that although the characteristic peaks of the PEGE segment did not directly show in ${ }^{1} \mathrm{H} N M R$, the peaks, $g$ and $h$, of the ethyl group, respectively, appeared at 66.5 and $14.6 \mathrm{ppm}$ in ${ }^{13} \mathrm{C}$ NMR. However, the above results indicated that deprotection quantitatively occurred in order to provide the copolymer PG-stat-PEGE without substituents at the $\alpha$-end. Additionally, we used SEC equipped with a multiangle laser light scattering (SEC-MALS) instrument to test their actual weighted average molecular weights $\left(\mathrm{M}_{\mathrm{w}, \mathrm{MALS}} \mathrm{s}\right)$, and the results for PG-stat-PEGE and PG-b-PEGE ranged from 7.2 to $9.7 \mathrm{~kg} \mathrm{~mol}^{-1}$ (entries 15-28 in Table 2). It is worth noting that as the $\alpha$-end of copolymers are $\mathrm{OH}$ groups without characteristic peaks, we adopted the SEC measurements equipped with multi-angle laser light-scattering (SECMALLS) instruments to provide their weight average molecular weights $\left(M_{\mathrm{w}, \text { MALS }} \mathrm{s}\right)$. As shown in Table 2 , the actual weight average molecular weight $\left(M_{\mathrm{W}, \mathrm{MALS}}\right)$ of the copolymers $\mathrm{PG}_{\mathrm{x}}$-stat-PEGE $\mathrm{y}$ and $\mathrm{PG}_{\mathrm{x}}-b-\mathrm{PEGE}_{\mathrm{y}}$ is in the range of 7.4-9.7 $\mathrm{kg} \mathrm{mol}^{-1}$. 
Table 2. Cloud-point temperature $\left(T_{\mathrm{cp}}\right)$ and average hydrodynamic radii $\left(D_{\mathrm{h}}\right)$ of PG-stat-PEGE and PG- $b$-PEGE prepared by debenzylation of PBnGE-stat-PEGE and PBnGE- $b$-PEGE, respectively, using Pd/C and $\mathrm{H}_{2}{ }^{a}$.

\begin{tabular}{|c|c|c|c|c|c|c|c|c|c|}
\hline \multirow{3}{*}{ Entry } & \multirow{3}{*}{ Starting Material } & \multicolumn{8}{|c|}{ Product } \\
\hline & & \multirow{2}{*}{ Code } & \multirow{2}{*}{$\begin{array}{l}M_{\mathrm{w}, \mathrm{MALS}}{ }^{b} \\
\left(\mathrm{~kg} \mathrm{~mol}^{-1}\right)\end{array}$} & \multirow{2}{*}{$M_{\mathrm{w}} / M_{\mathrm{n}}^{c}$} & \multirow{2}{*}{$\begin{array}{l}\text { Yield } \\
(\%)\end{array}$} & \multirow{2}{*}{$\begin{array}{l}T_{\mathrm{cp}}{ }^{d} \\
\left({ }^{\circ} \mathrm{C}\right)\end{array}$} & \multicolumn{3}{|c|}{$D_{\mathrm{h}}(\mathrm{nm})^{e}$} \\
\hline & & & & & & & $5^{\circ} \mathrm{C}$ & $30^{\circ} \mathrm{C}$ & $90^{\circ} \mathrm{C}$ \\
\hline 15 & \multirow{9}{*}{ PBnGE $E_{x}$ stat-PEGE $E_{y}$} & $\mathrm{PG}_{10}$-stat-PEGE 86 & 9.5 & 1.12 & 93.5 & 30.5 & 10.5 & - & 690 \\
\hline 16 & & $\mathrm{PG}_{20}$-stat-PEGE 79 & 9.5 & 1.11 & 91.4 & 37.0 & 8.9 & - & 704 \\
\hline 17 & & $\mathrm{PG}_{30}$-stat-PEGE 70 & 9.4 & 1.13 & 90.1 & 45.4 & 9.6 & - & 725 \\
\hline 18 & & $\mathrm{PG}_{40}$-stat-PEGE 60 & 9.1 & 1.11 & 91.9 & 50.5 & 9.9 & - & 719 \\
\hline 19 & & $\mathrm{PG}_{50}$-stat-PEGE 50 & 8.8 & 1.10 & 93.4 & 56.1 & 10.4 & - & 722 \\
\hline 20 & & $\mathrm{PG}_{60}$-stat-PEGE 40 & 8.5 & 1.13 & 92.6 & 62.2 & 10.1 & - & 731 \\
\hline 21 & & $\mathrm{PG}_{70}$-stat-PEGE 30 & 8.2 & 1.11 & 89.3 & 70.4 & 10.8 & - & 754 \\
\hline 22 & & $\mathrm{PG}_{78}$-stat-PEGE 20 & 7.8 & 1.13 & 90.7 & - & 12.3 & - & 92 \\
\hline 23 & & $\mathrm{PG}_{86}$-stat-PEGE 10 & 7.4 & 1.12 & 89.0 & - & 15.5 & - & 87 \\
\hline 24 & \multirow{5}{*}{$\mathrm{PBnGE}_{\mathrm{x}}-b-\mathrm{PEGE}_{\mathrm{y}}$} & $\mathrm{PG}_{10}-b-\mathrm{PEGE}_{88}$ & 9.7 & 1.14 & 89.3 & - & 19.3 & - & 54 \\
\hline 25 & & $\mathrm{PG}_{20}-b-\mathrm{PEGE}_{79}$ & 9.5 & 1.13 & 92.4 & - & 26.8 & - & 76 \\
\hline 26 & & $\mathrm{PG}_{30}-b-\mathrm{PEGE}_{70}$ & 9.4 & 1.13 & 93.1 & - & 24.5 & - & 58 \\
\hline 27 & & $\mathrm{PG}_{40}-b-\mathrm{PEGE}_{60}$ & 9.1 & 1.12 & 91.3 & - & 32.4 & 178 & 42 \\
\hline 28 & & $\mathrm{PG}_{50}-b-\mathrm{PEGE}_{50}$ & 8.8 & 1.13 & 90.5 & - & 38.2 & 268 & 40 \\
\hline
\end{tabular}

${ }^{a}$ Determined by the SEC equipped with a MALS in DMF in the presence of $0.01 \mathrm{M} \mathrm{LiCl} .{ }^{b}$ Determined by MALS in DMF containing $0.01 \mathrm{~mol} \mathrm{~L}-1 \mathrm{LiCl}\left(\mathrm{dn} / \mathrm{dc}, 0.0333 \mathrm{~mL} \mathrm{~g}^{-1}\right) .{ }^{c}$ Determined by SEC in DMF using PMMA standards. ${ }^{d}$ Determined by UV-vis measurements in water $\left(10 \mathrm{~g} \mathrm{~L}^{-1}\right) .{ }^{e}$ Determined by DLS measurements in water $\left(10 \mathrm{~g} \mathrm{~L}^{-1}\right)$.

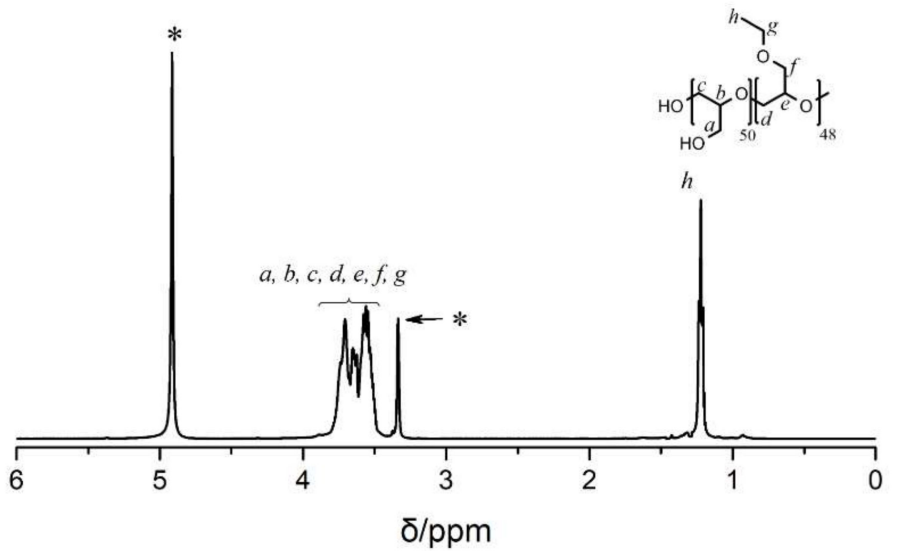

(a)

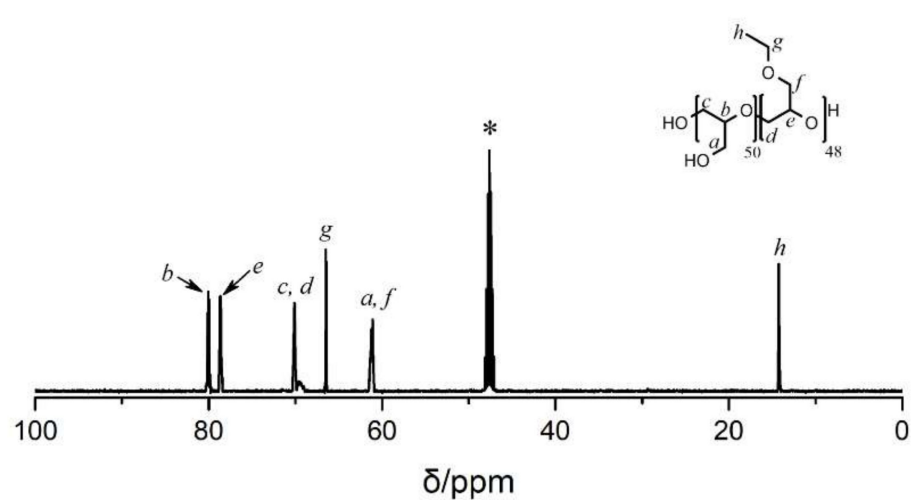

(b)

Figure 4. Typical ${ }^{1} \mathrm{H}$ NMR (a) and ${ }^{13} \mathrm{C}$ NMR (b) spectra of $\mathrm{PG}_{50}-b-\mathrm{PEGE}_{50}$ in MeOD (the symbol * refers to solvent peaks).

\subsection{Thermoresponsive Properties of $P G_{x}$-stat-PEGE $E_{y}$ and $P G_{x}-b-P E G E_{y}$}

The thermal phase-transition behavior of copolymers was determined by the transmittancevs-temperature curves; that is, the $T_{\mathrm{cp}}$ was defined as the temperature when the transmittance reached $50 \%$. The transmittance-vs-temperature curves are formed by monitoring the polymer solution at a concentration of $10 \mathrm{~g} \mathrm{~L}^{-1}$ with an ultraviolet-visible spectrophotometer at a wavelength of $500 \mathrm{~nm}$. Figure 5 shows the dependence of the transmittance of PG-stat-PEGE and PG- $b$-PEGE on temperature. Among the obtained copolymers, both PG-stat-PEGE and PG- $b$-PEGE were soluble in pure water at room temperature. It was found that the aqueous solution of $\mathrm{PG}_{10}$-stat-PEGE $86, \mathrm{PG}_{20}$-stat-PEGE $79, \mathrm{PG}_{30}$-stat-PEGE 70 , $\mathrm{PG}_{40}$-stat-PEGE $60, \mathrm{PG}_{50}$-stat-PEGE $50, \mathrm{PG}_{60}$-stat-PEGE 40 , and $\mathrm{PG}_{70}$-stat-PEGE 30 showed a sharp drop in transmittance when heated, indicating the existence of an T-type phase transition. In order to confirm the reversibility of the phase transition, we found that the optical transmittance of the solution returned to $100 \%$ after cooling, and the hysteresis was negligible. On the other hand, although $\mathrm{PG}_{78}$-stat-PEGE 20 and $\mathrm{PG}_{87}$-stat-PEGE 10 are completely soluble in water, the transmittance slightly decreases with increasing temperature. 
Surprisingly, it does not show any significant phase change at $90{ }^{\circ} \mathrm{C}$. The aqueous solution of $\mathrm{PG}_{x}$-stat-PEGE $y(\mathrm{x}=10,20,30,40,50,60$, and $70 ; \mathrm{y}=30,40,50,60,70,79$, and 86) reacts violently to thermal stimuli, as shown in Figure $5 \mathrm{a}$, and the $T_{\mathrm{cp}}$ are listed in Table 2 . For PG-stat-PEGE, we observed that $T_{\mathrm{cp}}$ increased with an increasing hydrophilic segment PG and a decreasing thermoresponsive segment PEGE, accompanied by decreasing of $M_{\mathrm{W}, \text { MALS}}$, which is usually observed in most thermoresponsive polymers. In other words, an earlier reduction in optical transmittance can be observed for $\mathrm{PG}_{x}$-stat-PEGE $y$ with a higher EGE ratio, which is in line with our expectations. When the value of PG unit $x$ increased to 78 and the value of PEGE unit y dropped to 20, it was difficult to exhibit LCST phase-transition behavior.

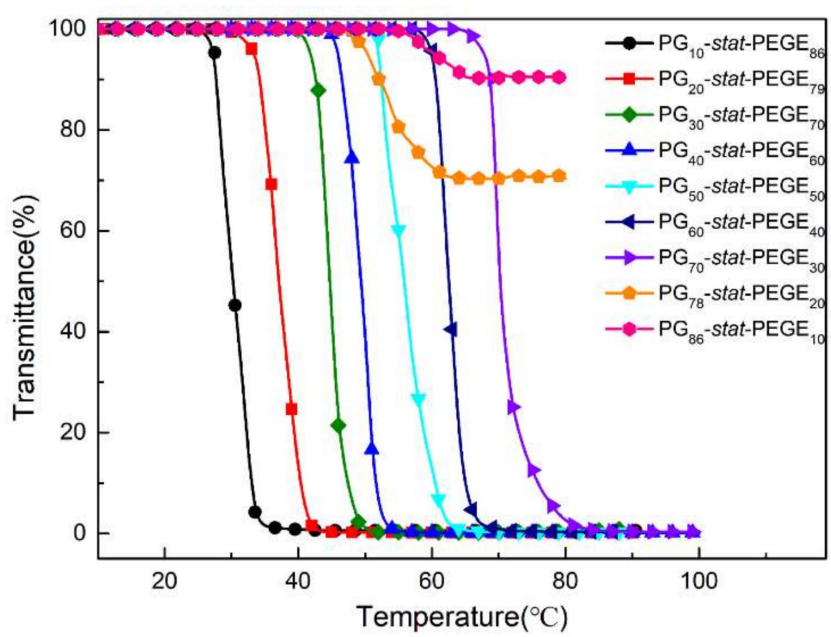

(a)

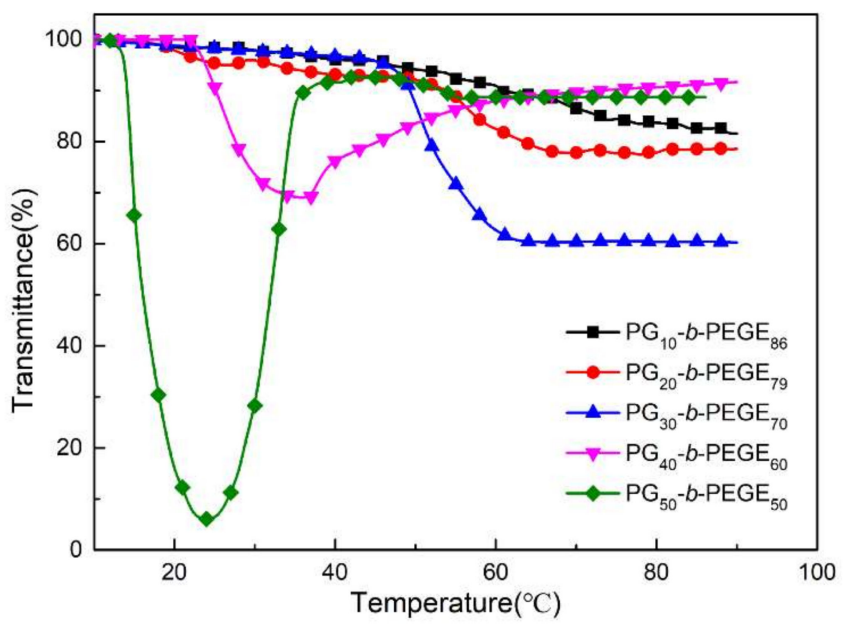

(b)

Figure 5. The cloud-point curves of (a) $\mathrm{PG}_{x}$-stat-PEGE $\mathrm{P}_{y}$ and (b) $\mathrm{PG}_{x}-b-\mathrm{PEGE}_{y}$ in the aqueous solutions $\left(10 \mathrm{~g} \mathrm{~L}^{-1}\right)$.

Different from PG-stat-PEGE's performance, $\mathrm{PG}_{10}-b-\mathrm{PEGE}_{86}, \mathrm{PG}_{20}-b$-PEGE 79 , and $\mathrm{PG}_{30}-b-\mathrm{PEGE}_{70}$ did not show a sharp drop in transmittance from $0{ }^{\circ} \mathrm{C}$ to $90{ }^{\circ} \mathrm{C}$, only slightly changing in transmittance. Interestingly, the transmittance of $\mathrm{PG}_{40}-b-\mathrm{PEGE}_{60}$ and $\mathrm{PG}_{50}-b$ $\mathrm{PEGE}_{50}$ in the range of $0-60^{\circ} \mathrm{C}$ appears to first decrease with increased temperature and then rise to a high value after further heating, as shown in Figure 5b. Similar results have occurred when we can decompose this special phase-change behavior into first LCST-type and then temperature (UCST)-like (actually not UCST) phase transitions. In summary, the $\mathrm{PG}_{x}-b-\mathrm{PEGE}_{y}$ phase transition significantly differs from that observed for $\mathrm{PG}_{x}-$ stat-PEGE $_{y}$ when the values of $x$ and $y$ are the same. In addition, taking the thermoresponsive property characteristics of $\mathrm{PG}_{50}-b$-PEGE 50 as an example, as shown in Figure 6, it can be concluded that the concentration of the polymer aqueous solution significantly affects the phasetransition process. In addition, the phase change becomes more obvious with increasing concentration, which may be attributed to the higher concentration and easier-to-form large aggregates. Therefore, in order to more directly understand the aggregation behavior of the polymer solution, we performed DLS measurements.

The hydrodynamic-diameter $\left(D_{\mathrm{h}}\right)$ results of $\mathrm{PG}_{x}$-stat-PEGE $\mathrm{PL}_{y}$ and $\mathrm{PG}_{x}-b-\mathrm{PEGE}_{y}$ are summarized in Table 2. As an example, $\mathrm{PG}_{50}$-stat-PEGE 50 was observed with a monodispersed distribution, and the $D_{\mathrm{h}}$ was 10.4 at $20{ }^{\circ} \mathrm{C}$, as shown in Figure $7 \mathrm{a}$. This value conforms to the order of a single polymer chain, which proves that there is only a single polymer chain in the solution. When at a high temperature of $70{ }^{\circ} \mathrm{C}$, the DLS measurement curve of $\mathrm{PG}_{50}$-stat-PEGE 50 still shows the monodispersed scattering distribution, whose $D_{\mathrm{h}}$ value calculated from the peak is $722 \mathrm{~nm}$, and it is used as a typical distribution of $\mathrm{PG}_{x}$-stat-PEGE $\mathrm{P}_{y}$ in Figure $7 \mathrm{~b}$. Obviously, the $D_{\mathrm{h}}$ results show that $\mathrm{PG}_{50}$-stat-PEGE ${ }_{50}$ forms uniform aggregates with larger particle sizes at a higher temperature than $T_{\mathrm{cp}}$, resulting in a polymer aqueous solution with a permeability of 0 . For $P_{50}-b-P_{E G E}$, there is a 
two-stage phase transition during the heating process; that is, the average measured value of $D_{\mathrm{h}}$ is only $9.6 \mathrm{~nm}$ at $5{ }^{\circ} \mathrm{C}$. It rose to $268 \mathrm{~nm}$ quickly when the temperature increased to $25^{\circ} \mathrm{C}$. The $D_{\mathrm{h}}$ then undergoes a second transition to $26 \mathrm{~nm}$ due to heating to $40{ }^{\circ} \mathrm{C}$. We consider that there may be a micelle-like structure at $10^{\circ} \mathrm{C}$, so in the first stage of raising the temperature, the micelles aggregate to form large aggregates with a uniform $D_{\mathrm{h}}$ of $268 \mathrm{~nm}$. After the second stage of heating to above $40^{\circ} \mathrm{C}, D_{\mathrm{h}}$ decreased to $40 \mathrm{~nm}$, and the aggregates rearranged to form more stable, tiny aggregates. In other words, the solution is in a metastable system state at $25^{\circ} \mathrm{C}$, and a phase transition from the first stage to the second stage can occur when the temperature reaches $45^{\circ} \mathrm{C}$. Comparing the phase-transition behavior of $\mathrm{PG}_{x}$-stat-PEGE $y$ and $\mathrm{PG}_{x}-b-\mathrm{PEGE}_{y}$, we infer that the phase-transition behavior is completely different due to the disorder of the polymer chain. In order to demonstrate the point of disorder, we designed the synthesis of multiblock copolymers.

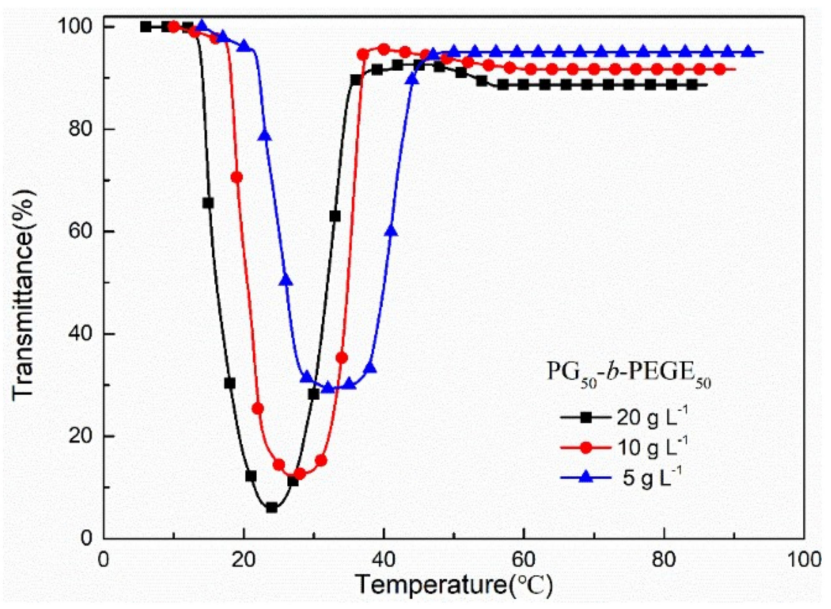

Figure 6. The thermal phase-transition curves at different concentrations of $\mathrm{PG}_{50}-b-\mathrm{PEGE}_{50}$.

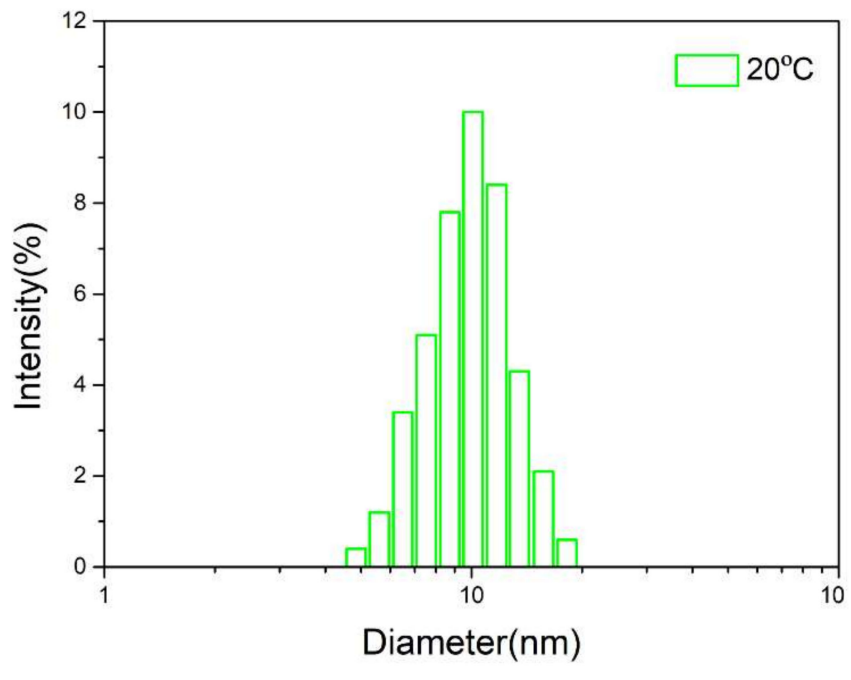

(a)

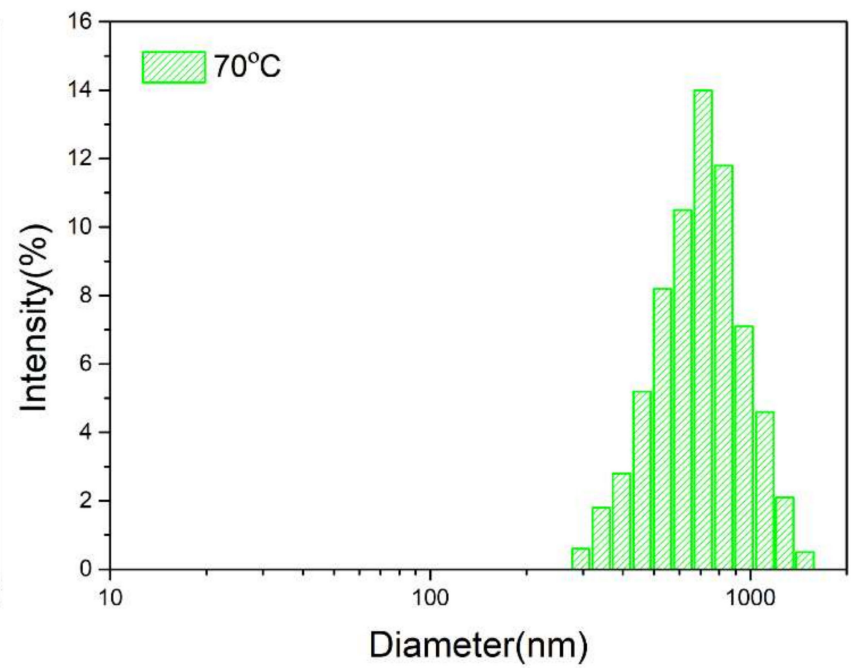

(b)

Figure 7. Hydrodynamic diameter distribution of $\mathrm{PG}_{50}$-stat-PEGE 50 at (a) $20^{\circ} \mathrm{C}$, and (b) $70{ }^{\circ} \mathrm{C}\left(\right.$ scattering angle, $90^{\circ}$ ).

\subsection{Thermoresponsive Properties of Multiblock Copolymer and Homopolymer}

In order to evaluate the thermoresponsive properties of multiblock polymers, we designed and synthesized four triblock copolymers, $\mathrm{PG}_{15}-b$ - $\mathrm{PEGE}_{70}-b-\mathrm{PG}_{15}, \mathrm{PG}_{35}-b-\mathrm{PEGE}_{30}-$ $b$ - $\mathrm{PG}_{35}, \mathrm{PEGE}_{15}-b-\mathrm{PG}_{70}-b-\mathrm{PEGE}_{15}$, and $\mathrm{PEGE}_{35}-b-\mathrm{PG}_{30}-b-\mathrm{PEGE}_{35}$. As shown in Figure $8 \mathrm{a}, \mathrm{b}$, our analysis shows that the thermal-response behavior of these four triblock copolymers 
significantly depends on the ratio of PG/PEGE. As observed, $\mathrm{PEGE}_{35}-b-\mathrm{PG}_{30}-b-\mathrm{PEGE}_{35}$ showed a typical LCST-type phase transition, and $\mathrm{PG}_{15}-b-\mathrm{PEGE}_{70}-b-\mathrm{PG}_{15}$ and $\mathrm{PEGE}_{15}-b-$ $\mathrm{PG}_{70}-b$-PEGE 15 showed a two-stage phase transition. However, $\mathrm{PG}_{35}-b-\mathrm{PEGE}_{30}-b-\mathrm{PG}_{35}$ showed little change in transmittance. $\mathrm{PEGE}_{35}-b-\mathrm{PG}_{30}-b-\mathrm{PEGE}_{35}$ shows a typical LCST-type phase transition with a $T_{\mathrm{cp}}$ of $49.8^{\circ} \mathrm{C}$ (Table S2). The thermal-response behaviors of $\mathrm{PG}_{35}-$ $b$ - $\mathrm{PEGE}_{30}-b-\mathrm{PG}_{35}$ and $\mathrm{PEGE}_{15}-b-\mathrm{PG}_{70}-b-\mathrm{PEGE}_{15}$ are very similar to the diblock copolymer of $\mathrm{PG}_{50}-b-\mathrm{PEGE}_{50}$ (Figure $5 \mathrm{~b}$, Table 2), in which transmittance reached close to $0 \%$ at the inflection point of the phase change. In addition, although the transmittance of $\mathrm{PG}_{15}-b$ $\mathrm{PEGE}_{70}-b-\mathrm{PG}_{15}$ decreased after the temperature was raised to $30^{\circ} \mathrm{C}$, the transmittance no longer decreased when it reached $55 \%$ at $50{ }^{\circ} \mathrm{C}$. The $T_{\mathrm{cp}}$ of $\mathrm{PEGE}_{20}-b-\mathrm{PG}_{20}-b-\mathrm{PEGE}_{20}-b-$ $\mathrm{PG}_{20}-b-\mathrm{PEGE}_{20}$ and $\mathrm{PG}_{20}-b-\mathrm{PEGE}_{20}-b-\mathrm{PG}_{20}-b-\mathrm{PEGE}_{20}-b-\mathrm{PG}_{20}$ results shown in Figure $8 c$ were 48.3 and $61.7^{\circ} \mathrm{C}$, respectively. In addition, although their $M_{\mathrm{W}, \mathrm{MALS}}$ are similar to each other in Table S4, it is not difficult to find that the higher percentage of EGE units tends to have lower $T_{\mathrm{cp}}$. It should be noted that the pentablock copolymers $\mathrm{PEGE}_{20}-b-\mathrm{PG}_{20}-$ $b$ - $\mathrm{PEGE}_{20}-b-\mathrm{PG}_{20}-b-\mathrm{PEGE}_{20}$ and $\mathrm{PG}_{20}-b-\mathrm{PEGE}_{20}-b-\mathrm{PG}_{20}-b-\mathrm{PEGE}_{20}-b-\mathrm{PG}_{20}$ both exhibited LCST-type phase transitions in aqueous solutions, which were in sharp contrast to the results of triblock and diblock copolymers. Finally, we confirmed our conjecture that the dependence of $T_{\mathrm{cp}}$ on the disorder of copolymers is undeniable. However, the exact of cause this phenomenon is unclear.

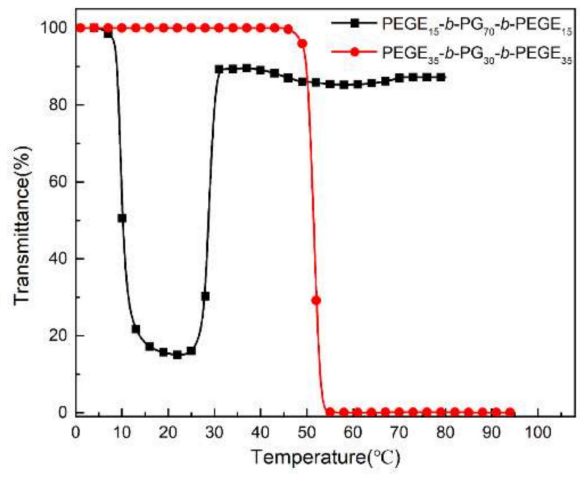

(a)

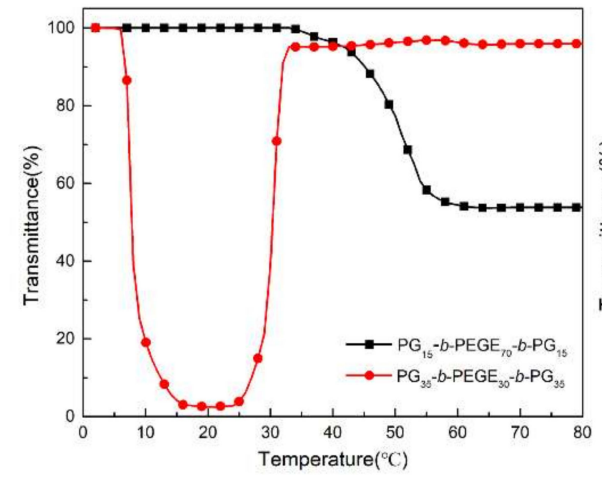

(b)

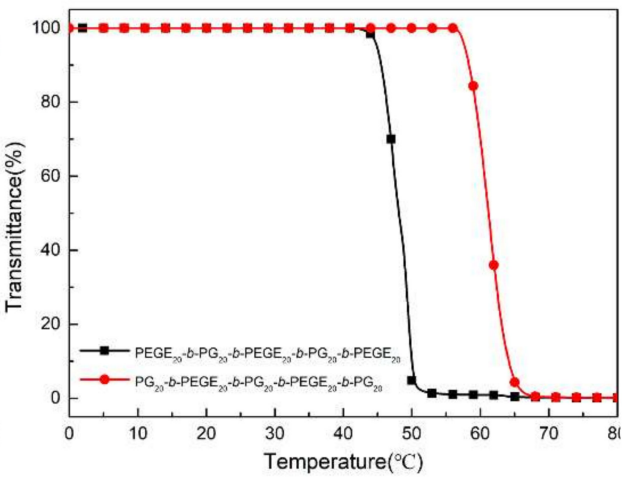

(c)

Figure 8. The thermal phase-transition curves at different concentrations of (a) PEGE $15-b-\mathrm{PG}_{70}-b-\mathrm{PEGE}_{15}$ and $\mathrm{PEGE} 35-b-$ $\mathrm{PG}_{30}-b-\mathrm{PEGE}_{35}$, (b) $\mathrm{PG}_{15}-b-\mathrm{PEGE}_{70}-b-\mathrm{PG}_{15}$ and $\mathrm{PG}_{35}-b-\mathrm{PEGE}_{30}-b-\mathrm{PG}_{35}$, (c) PEGE $20-b-\mathrm{PG}_{20}-b-\mathrm{PEGE}_{20}-b-\mathrm{PG}_{20}-b-\mathrm{PEGE}_{20}$ and $\mathrm{PG}_{20}-b-\mathrm{PEGE}_{20}-b-\mathrm{PG}_{20}-b-\mathrm{PEGE}_{20}-b-\mathrm{PG}_{20}$ in $10 \mathrm{~g} \mathrm{~L}^{-1}$.

As one example, Figure $\mathrm{S} 2$ shows the ${ }^{1} \mathrm{H}$ NMR spectra of $\mathrm{PEGE}_{15}-b-\mathrm{PG}_{70}-b-\mathrm{PEGE}_{15}$ with the temperature changed in $\mathrm{D}_{2} \mathrm{O}$. Since the instrument cannot cool down at room temperature, the temperatures were initially set to $23^{\circ} \mathrm{C}$, increased to $33^{\circ} \mathrm{C}$ and $43^{\circ} \mathrm{C}$, then finally cooled to $23{ }^{\circ} \mathrm{C}$. For the initial $23{ }^{\circ} \mathrm{C}$ measurement, the signals of the main chains and side groups could be clearly observed at 3.81-3.22 ppm (a, b, c, d). The signals obviously shifted to the low magnetic-field regions when the temperature increased from $23{ }^{\circ} \mathrm{C}$ to $43{ }^{\circ} \mathrm{C}$. Similar tendencies were observed for the other signals in the range of 1.03-1.27 ppm (e). This result can be explained by the theory that the electron densities of the protons decrease due to intramolecular/intermolecular bond interactions, resulting in the shift of the signals to the low magnetic-field regions. Notably, the signals were not significantly broadened but significantly enhanced by the increasing temperature. We cannot provide a reliable explanation for this unexpected result, but the enhancement of the signal corresponds to this increase in transmittance behavior. For the final $23^{\circ} \mathrm{C}$ measurements, the spectral profile agreed with that of the initial one, proving that the phase-transition phenomenon is reversible. In order to further determine the interesting phase-transition behavior, we performed DLS measurements on these multiblock polymers to understand the polymer at each stage of the phase-transition hydrodynamic diameter 
$\left(D_{\mathrm{h}}\right)$ at 20 and $60{ }^{\circ} \mathrm{C}$. At high temperatures above $60{ }^{\circ} \mathrm{C}$, DLS measurements show a monodispersed scattering distribution, which is a typical distribution curve for $\mathrm{PG}_{15}-b$ $\mathrm{PEGE}_{70}-b-\mathrm{PG}_{15}$ (Figure S3). For $\mathrm{PG}_{15}-b-\mathrm{PEGE}_{70}-b-\mathrm{PG}_{15}$, the $D_{\mathrm{h}}$ at $60{ }^{\circ} \mathrm{C}$ is calculated as $545 \mathrm{~nm}$. The results showed that although the light transmittance did not reach $0 \%, \mathrm{PG}_{15^{-}}$ $b$ - $\mathrm{PEGE}_{70}-b-\mathrm{PG}_{15}$ had formed stable and uniform aggregates upon $T_{\mathrm{cp}}$ attributed to the formed aggregates were not observed to aggregate further. In addition, the $D_{\mathrm{h}}$ values of $\mathrm{PEGE}_{15}-b-\mathrm{PG}_{70}-b-\mathrm{PEGE}_{15}, \mathrm{PEGE}_{35}-b-\mathrm{PG}_{30}-b-\mathrm{PEGE}_{35}, \mathrm{PG}_{35}-b-\mathrm{PEGE}_{30}-b-\mathrm{PG}_{35}, \mathrm{PEGE}_{20}-b-$ $\mathrm{PG}_{20}-b-\mathrm{PEGE}_{20}-b-\mathrm{PG}_{20}-b-\mathrm{PEGE}_{20}$, and $\mathrm{PG}_{20}-b-\mathrm{PEGE}_{20}-b-\mathrm{PG}_{20}-b-\mathrm{PEGE}_{20}-b-\mathrm{PG}_{20}$ are shown in Table S4.

We considered that while exploring the thermoresponsive property of the copolymer of PG and PEGE, it should be necessary to explore the homopolymer of PEGE to compare. Our group reported the synthesis of PEGE with the $n$-butoxy group as the $\alpha$-chain end in previous studies [34]. However, we first used $t \mathrm{BBA}$ as an initiator to carry out ring-opening polymerization to obtain $t$ BBA-PEGE in order to obtain the PEGE with a hydroxyl group at the $\alpha$-chain end. Here, we designed the ratio of the initial monomer to the initiator $\left([\mathrm{M}]_{0} /[t \mathrm{BBA}]\right)$ to be $25,50,75$, and 100 to produce $t$ BBA-PEGE with different molecular weights, which is obtained with a corresponding molecular weight of $2.7-10.4 \mathrm{~kg} \mathrm{~mol}^{-1}$ (Table S5). In addition, by observing the signal displayed by the ${ }^{1} \mathrm{H}$ NMR spectrum, we can confirm that the resulting product affords a $t$ BBA group at the end of the $\alpha$-chain (Figure S4a). For the ${ }^{13} \mathrm{C}$ NMR spectrum (Figure S4b), not only did the three signals appear at 61.0, 79.5, and $69.4 \mathrm{ppm}(\mathrm{a}, \mathrm{b}$, and c, respectively), but the signals of tBBA can also be observed. Figure S5 shows the matrix-assisted laser-desorption ionization time-of-flight mass spectrometry (MALDI-TOF MS) spectrum, which provides favorable evidence for the structure assignment of $t$ BBA-PEGE. It can be seen from Figure 9a that the aqueous solutions of $t \mathrm{BBA}-\mathrm{PEGE}_{25,50,75,100}$ all become opaque during heating, indicating the existence of the LCST-type phase transition. As listed in Table S5, the $T_{\mathrm{cp}} \mathrm{S}$ of the polyethers were observed in the temperature range of $9.1-12.1^{\circ} \mathrm{C}$ and increased in the following order: $t$ BBA-PEGE $100\left(9.1^{\circ} \mathrm{C}\right)<t$ BBA-PEGE $_{75}\left(10.4^{\circ} \mathrm{C}\right)<t \mathrm{BBA}^{\circ} \mathrm{PEGE}_{50}\left(11.5^{\circ} \mathrm{C}\right)$ $<$ BBA-PEGE $25\left(12.1^{\circ} \mathrm{C}\right)$.

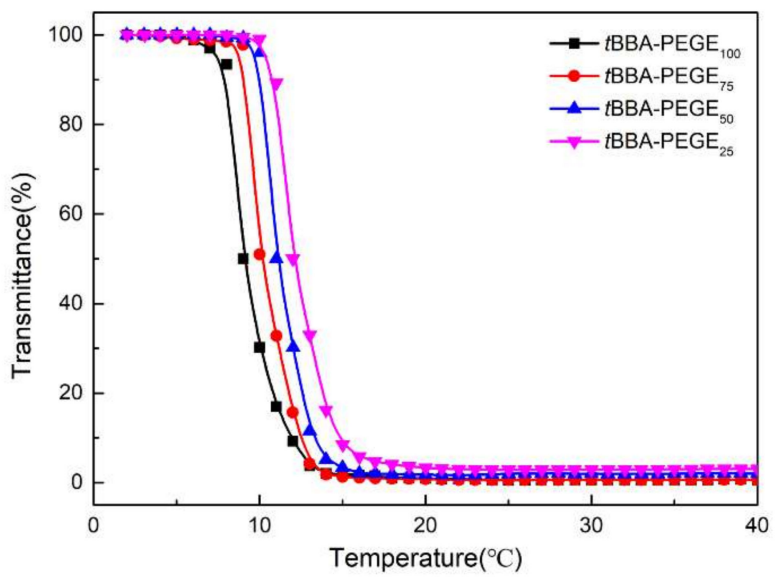

(a)

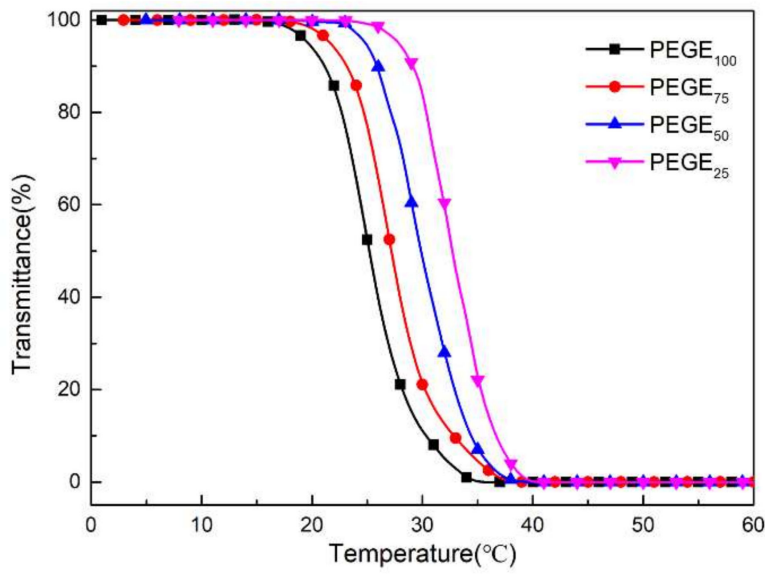

(b)

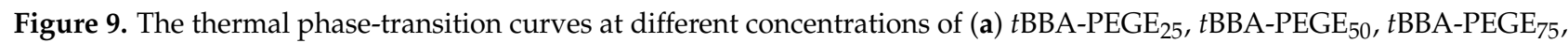
and $t$ BBA-PEGE 100 and (b) PEGE $_{25}$, PEGE $_{50}, \mathrm{PEGE}_{75}$, and $\mathrm{PEGE}_{100}$.

We synthesized the polymer PEGE with the $\alpha$-chain end as the hydroxyl group through deprotection experiments and through a ${ }^{1} \mathrm{H}$ NMR spectrum test to confirm that the $t$ BBA group of the previous $\alpha$-chain end had disappeared. In Figure S6, two signals appeared at 1.23-1.42 ppm and 3.48-3.85 ppm (e and $a, b, c, d$, respectively). The size exclusion chromatography (SEC) experiment (Figure S7) with the obtained products, PEGE, showed that the narrow dispersions $\left(M_{\mathrm{w}} / M_{\mathrm{n}}\right)$ were less than 1.10 . However, these results 
indicated that we successfully afforded PEGE without substituents in both ends of the chain after deprotection. The aqueous solutions of PEGE $\left(10 \mathrm{~g} \mathrm{~L}^{-1}\right)$ were characterized by UV-Vis spectroscopy to determine their $T_{\mathrm{cp}} \mathrm{S}$, which are listed in Table S6. The $T_{\mathrm{cp}}$ value of PEGE $25,50,75,100$ was in the range of 25.2 to $32.5^{\circ} \mathrm{C}$, as shown in Figure $9 \mathrm{~b}$. It is easy to find that both $t$ BBA-PEGE and PEGE follow the same rule that $T_{\mathrm{cp}}$ will decrease as the degree of polymerization increases. The exciting phenomenon is that PEGE with the same degree of polymerization has a higher $T_{\mathrm{cp}}$ value than $t \mathrm{BBA}-\mathrm{PEGE}$, so we consider the $\alpha$-end group has a considerable influence on the thermoresponsive property of the polymer. We further performed the DLS measurement of PEGE to monitor the $D_{\mathrm{h}}$ at different temperatures. Figure S8 depicts the curve of hydrodynamic diameter $\left(D_{\mathrm{h}}\right)$ before and after the phase transition of PEGE ${ }_{50}$. Thus, we concluded that the thermal-response behavior of $t$ BBA-PEGE and PEGE made our research on the thermoresponsive properties of its copolymers more colorful.

\section{Conclusions}

The ROP, using the combination of $t-\mathrm{Bu}-\mathrm{P}_{4}$ and the $t \mathrm{BBA}$ initiator, was efficient for synthesizing PBnGE-stat-PEGE and PBnGE-b-PEGE in different DPs with the intended molecular weights and relatively narrow molecular weight distributions, the controlled/living nature of could also afford PG-stat-PEGE and PG-b-PEGE. PG -stat-PEGE $_{\mathrm{y}}$ exhibited LCSTtype thermal-response behavior, and adjusting the $\mathrm{x} / \mathrm{y}$ value caused a cloud-point temperature $\left(T_{\mathrm{cp}}\right)$ in the range of 30.5 to $70.4^{\circ} \mathrm{C}$, which may expand its application possibilities. To further study the thermal-response behavior of its copolymers, we synthesized triblock and pentablock copolymers. Therefore, we found that $\mathrm{PEGE}_{35}-b-\mathrm{PG}_{30}-b-\mathrm{PEGE}_{35}, \mathrm{PEGE}_{20}-$ $b-\mathrm{PG}_{20}-b-\mathrm{PEGE}_{20}-b-\mathrm{PG}_{20}-b-\mathrm{PEGE}_{20}$, and $\mathrm{PG}_{20}-b-\mathrm{PEGE}_{20}-b-\mathrm{PG}_{20}-b-\mathrm{PEGE}_{20}-b-\mathrm{PG}_{20}$ exhibited LCST-type phase transition. For $\mathrm{PG}_{\mathrm{x}}-b-\mathrm{PEGE}_{\mathrm{y}}$, the phase-change behavior shows two stages. LCST-type is the first phase-change stage. UCST-like (not UCST) is the second phasechange stage, which is similar to $\mathrm{PG}_{35}-b-\mathrm{PEGE}_{30}-b-\mathrm{PG}_{35}$ and $\mathrm{PEGE}_{15}-b-\mathrm{PG}_{70}-b-\mathrm{PEGE}_{15}$. In addition, we found that PEGE homopolymers without specific $\alpha$-chain ends also exhibited regular thermoresponsive properties. In general, the properties of all copolymer structures were evaluated, and the importance of copolymer disorder to thermoresponsive properties is emphasized.

Supplementary Materials: The following are available online at https://www.mdpi.com/article/ 10.3390/polym13223873/s1, Table S1: Synthesis of PBnGE-b-PEGE- $b$-PBnGE and PEGE-b-PBnGE$b$-PEGE by block ROP of BnGE and EGE using $t \mathrm{BBA}$ as the initiator and $t-\mathrm{Bu}-\mathrm{P}_{4}$ as the catalyst, Table S2: Cloud-point temperature $\left(T_{\mathrm{cp}}\right)$ and average hydrodynamic radii $\left(D_{\mathrm{h}}\right)$ of PG- $b$-PEGE- $b$-PG and PEGE- $b$-PG- $b$-PEGE, prepared by the debenzylation of PBnGE- $b$-PEGE- $b$-PBnGE and PEGE- $b$ PBnGE- $b$-PEGE, respectively, Table S3: Synthesis of PBnGE- $b$-PEGE- $b$-PBnGE- $b$-PEGE- $b$-PBnGE and PEGE- $b$-PBnGE- $b$-PEGE- $b$-PBnGE- $b$-PEGE by block ROP of BnGE and EGE using $t$ BBA as the initiator and $t$-Bu- $\mathrm{P}_{4}$ as the catalyst, Table S4: Cloud-point temperature $\left(T_{\mathrm{cp}}\right)$ and average hydrodynamic radii $\left(D_{\mathrm{h}}\right)$ of $\mathrm{PG}_{20}-b-\mathrm{PEGE}_{20}-b-\mathrm{PG}_{20}-b-\mathrm{PEGE}_{20}-b-\mathrm{PG}_{20}$ and $\mathrm{P} \mathrm{PEGE}_{20}-b-\mathrm{PG}_{20}-b-\mathrm{PEGE}_{20}-b-\mathrm{PG}_{20}-b-\mathrm{PEGE}_{20}$ prepared by the debenzylation of $\mathrm{PBnGE}_{20}-b-\mathrm{PEGE}_{20}-b-\mathrm{PBnGE}_{20}-b-\mathrm{PEGE}_{20}-b-\mathrm{PBnGE}_{20}$ and $\mathrm{PEGE}_{20}-b-$ $\mathrm{PBnGE}_{20}-b$ - $\mathrm{PEGE}_{20}-b-\mathrm{PBnGE}_{20}-b-\mathrm{PEGE}_{20}$, respectively, Table S5: Cloud-point temperature $\left(T_{\mathrm{cp}}\right)$ and average hydrodynamic radii $\left(D_{\mathrm{h}}\right)$ of $t$ BBA-PEGE prepared by ROP of EGE using $t \mathrm{BBA}$ as the initiator and $t$-Bu- $\mathrm{P}_{4}$ as the catalyst, Table S6: Cloud-point temperature $\left(T_{\mathrm{cp}}\right)$ and average hydrodynamic radii $\left(D_{\mathrm{h}}\right)$ of PEGE prepared by the debenzylation of $t$ BBA-PEGE using Pd/C and $\mathrm{H}_{2}$, Figure S1: SEC trace of (a) $\mathrm{PG}_{10}$-stat-PEGE 86 , (b) $\mathrm{PG}_{20}$-stat-PEGE 79 , (c) $\mathrm{PG}_{30}$-stat-PEGE 60 , (d) $\mathrm{PG}_{40}$-stat-PEGE 60 , (e) $\mathrm{PG}_{50}$ stat-PEGE 50 (f) $\mathrm{PG}_{60}$-stat-PEGE 40 , (g) $\mathrm{PG}_{70}$-stat-PEGE 30 , (h) PG $\mathrm{PG}_{78}$-stat-PEGE 20 , (i) $\mathrm{PG}_{86}$-stat-PEGE 10 in DMF, Figure S2: ${ }^{1} \mathrm{H}$ NMR spectra of $\mathrm{PEGE}_{15}-b$ - $\mathrm{PG}_{70}-b$-PEGE 15 at $23{ }^{\circ} \mathrm{C}, 33^{\circ} \mathrm{C}, 43{ }^{\circ} \mathrm{C}$, and $23^{\circ} \mathrm{C}$ (cooling to $23^{\circ} \mathrm{C}$ ) in $\mathrm{D}_{2} \mathrm{O}$, Figure S3: Hydrodynamic diameter distribution of $\mathrm{PG}_{15}-b-\mathrm{PEGE}_{70}-b$ - $\mathrm{PG}_{15}$ at (a) $20^{\circ} \mathrm{C}$, and (b) $60^{\circ} \mathrm{C}$ (scattering angle, $90^{\circ}$ ), Figure S4: (a) ${ }^{1} \mathrm{H}$ NMR and (b) ${ }^{13} \mathrm{C}$ NMR spectra of $t \mathrm{BBA}^{\mathrm{PEGE}} 25$ in MeOD (the symbol * refers to solvent peaks), Figure S5: MALDI-TOF MS spectrum of $t$ BBA-PBnGE 25 , Figure S6: ${ }^{1} \mathrm{H}$ NMR and spectra of PEGE 50 in MeOD (the symbol * refers to solvent peaks), Figure S7: SEC trace of $\mathrm{PEGE}_{25,50,75,100}$ in DMF, Figure S8: Hydrodynamic diameter distribution of $\mathrm{PEGE}_{50}$ at (a) $10{ }^{\circ} \mathrm{C}$ and (b) $45^{\circ} \mathrm{C}$ (scattering angle, $90^{\circ}$ ). 
Author Contributions: Conceptualization, T.K. and T.H.; methodology, X.S., Y.W. and L.X.; validation, T.H.; formal analysis, S.-i.S.; investigation, T.H. and Y.W.; data curation, T.H. and L.X.; writing-original draft preparation, T.H. and Y.W.; writing-review and editing, T.H., A.N. and T.K.; supervision, X.S.; funding acquisition, X.S. and T.K. All authors have read and agreed to the published version of the manuscript.

Funding: This research was funded by the Recruitment Program of Global Experts, China; Japan Society for the Promotion of Science, grant number JP17K05025; Jilin Provincial Department of Education Fund, grant number 6012100010111; and the Youth Fund of Changchun University of Science And Technology, grant number 201905010029.

Institutional Review Board Statement: Not applicable.

Informed Consent Statement: Not applicable.

Data Availability Statement: The data presented in this study are available on request from the corresponding author.

Acknowledgments: We would like to acknowledge Sato for the financial support from JSPS KAKENHI (Grant-in-Aid for Scientific Research (C) Searching for fluctuation-controllable self-assembled supramolecular systems and elucidation of their control mechanisms).

Conflicts of Interest: The authors declare no conflict of interest.

\section{References}

1. Xu, R.; Tian, J.; Guan, Y.; Zhang, Y. Extraordinarily Large LCST Depression Converts Nonthermosensitive Polymer to Thermosensitive. Macromolecules 2019, 52, 365-375. [CrossRef]

2. Weber, C.; Hoogenboom, R.; Schubert, U.S. Temperature responsive bio-compatible polymers based on poly(ethylene oxide) and poly(2-oxazoline)s. Prog. Polym. Sci. 2012, 37, 686-714. [CrossRef]

3. Hodorog, A.D.R.; Ibanescu, C.; Moleavin, L.; Hurduc, N. Thermo-responsiveness of polysiloxanes grafted with poly(dimethyl acrylamide) segments. Cen. Eur. J. Chem. 2012, 10, 1338-1348. [CrossRef]

4. $\mathrm{Hu}, \mathrm{J} . ; \mathrm{Liu}, \mathrm{S}$. Responsive Polymers for Detection and Sensing Applications: Current Status and Future Developments. Macromolecules 2010, 43, 8315-8330. [CrossRef]

5. Smith, A.E.; Xu, X.; McCormick, C.L. Stimuli-responsive amphiphilic (co)polymers via RAFT polymerization. Prog. Polym. Sci. 2010, 35, 45-91. [CrossRef]

6. Labbe, A.; Carlotti, S.; Deffieux, A.; Hirao, A. Controlled Polymerization of Glycidyl Methyl Ether Initiated by Onium Salt/Triisobutylaluminum and Investigation of the Polymer LCST. In Macromolecular Symposia; Wiley-VCH: Weinheim, Germany, 2007; Volume 249, pp. 392-397.

7. Lee, S.; Lee, J.-S.; Lee, C.H.; Jung, Y.-S.; Kim, J.-M. Nonpolymeric Thermosensitive Benzenetricarboxamides. Langmuir 2011, 27, 1560-1564. [CrossRef]

8. Ifuku, S.; Kadla, J.F. Preparation of a Thermosensitive Highly Regioselective Cellulose/N-Isopropylacrylamide Copolymer through Atom Transfer Radical Polymerization. Biomacromolecules 2008, 9, 3308-3313. [CrossRef]

9. Danko, M.; Kronekova, Z.; Mrlik, M.; Osicka, J.; Yousaf, A.B.; Durackova, A.; Tkac, J.; Kasak, P. Sulfobetaines Meet Carboxybetaines: Modulation of Thermo- and Ion-Responsivity, Water Structure, Mechanical Properties, and Cell Adhesion. Langmuir 2019, 35, 1391-1430. [CrossRef]

10. Woodfield, P.A.; Zhu, Y.; Pei, Y.; Roth, P.J. Hydrophobically Modified Sulfobetaine Copolymers with Tunable Aqueous UCST through Postpolymerization Modification of Poly(pentafluorophenyl acrylate). Macromolecules 2014, 47, 750-762. [CrossRef]

11. Lewoczko, E.M.; Wang, N.; Lundberg, C.E.; Kelly, M.T.; Kent, E.W.; Wu, T.; Chen, M.-L.; Wang, J.-H.; Zhao, B. Effects of N-Substituents on the Solution Behavior of Poly(sulfobetaine methacrylate)s in Water: Upper and Lower Critical Solution Temperature Transitions. ACS Appl. Polym. Mater. 2021, 3, 867-878. [CrossRef]

12. Chen, Y.; Xiao, N.; Fukuoka, M.; Yoshida, K.; Duan, Q.; Satoh, T.; Kakuchi, T. Synthesis and thermoresponsive properties of four-arm star-shaped poly( $N$-isopropylacrylamide)s bearing covalent and non-covalent cores. Polym. Chem. 2015, 6, 3608-3616. [CrossRef]

13. Kolouchova, K.; Lobaz, V.; Benes, H.; Rosa, V.R.D.L.; Babuka, D.; Svec, P.; Cernoch, P.; Hruby, M.; Hoogenboom, R.; Stepanek, P.; et al. Thermoresponsive properties of polyacrylamides in physiological solutions. Polym. Chem. 2021, 12, 5077-5084. [CrossRef]

14. Suzuki, T.; Kato, T.; Shinozaki, H. Photo-reversible $\mathrm{Pb}^{2+}$ complexation of thermosensitive poly( $N$-isopropyl acrylamide-cospiropyran acrylate) in water. Chem. Commun. 2004, 18, 2036-2037. [CrossRef] [PubMed]

15. Beattie, D.A.; Mensah, J.A.; Beaussart, A.; Franks, G.V.; Yeap, K.-Y. In situ particle film ATR FTIR spectroscopy of poly(N-isopropyl acrylamide) (PNIPAM) adsorption onto talc. Phys. Chem. Chem. Phys. 2014, 16, 25143-25151. [CrossRef]

16. Futscher, M.H.; Philipp, M.; Buschbaum, P.M.; Schulte, A. The Role of Backbone Hydration of Poly(N-isopropyl acrylamide) Across the Volume Phase Transition Compared to its Monomer. Sci. Rep. 2017, 7, 17012-17022. [CrossRef] 
17. Cui, H.-W.; Chu, W.-C.; Chen, J.-K.; Kuo, S.-W. Complementary multiple hydrogen bonds stabilize thermo-sensitive supramolecular structures prepared from poly( $N$-isopropyl acrylamide) and adenine-functionalized poly(ethylene oxide). Eur. Polym. J. 2014, 50, 168-176. [CrossRef]

18. Penas, A.G.; Wang, Y.; Bonilla, A.M.; García, M.F.; Stadler, F.J. Lower Critical Solution Temperature Sensitivity to Structural Changes in Poly(N-Isopropyl Acrylamide) Homopolymers. J. Polym. Sci. B Polym. Phys. 2019, 57, 1386-1393. [CrossRef]

19. Swanson, J.P.; Cruz, M.A.; Monteleone, L.R.; Martinez, M.R.; Costanzo, P.J.; Joy, A. The Effect of Pendant Group Structure on the Thermoresponsive Properties of N-Substituted Polyesters. Polym. Chem. 2017, 8, 7195-7206. [CrossRef]

20. Chen, S.; Wang, K.; Zhang, W. A new thermoresponsive polymer of poly(N-acryloylsarcosine methyl ester) with tunable LCST. Polym. Chem. 2017, 8, 3090-3101. [CrossRef]

21. Tong, J.-G.; Wei, Z.-Y.; Yang, H.-L.; Yang, Z.-Y.; Chen, Y. Study on the phase transition behaviors of thermoresponsive hyperbranched polyampholytes in water. Polymer 2016, 84, 107-116. [CrossRef]

22. Dong, Q.; Luo, C.; Li, N.; Chi, J.; Zhang, Q. Temperature and Recognition Dual Responsive Poly(N-Isopropylacrylamide) and Poly(N, N-Dimethylacrylamide) with Adamantyl Side Group. Materials 2018, 11, 473. [CrossRef] [PubMed]

23. Yu, J.; Chao, H.; Li, G.; Tang, R.; Liu, Z.; Liu, Z.; Jiang, J. Backbone-Based LCST-Type Hyperbranched Poly(oligo(ethylene glycol)) with $\mathrm{CO}_{2}$-Reversible Iminoboronate Linkers. Macromol. Chem. Phys. 2018, 219, 1800346. [CrossRef]

24. Topp, M.D.C.; Dijkstra, P.J.; Talsma, H.; Feijen, J. Thermosensitive Micelle-Forming Block Copolymers of Poly(ethylene glycol) and Poly(N-isopropylacrylamide). Macromolecules 1997, 30, 8518-8520. [CrossRef]

25. Pelletier, M.; Babin, J.; Tremblay, L.; Zhao, Y. Investigation of a New Thermosensitive Block Copolymer Micelle: Hydrolysis, Disruption, and Release. Langmuir 2008, 24, 12664-12670. [CrossRef] [PubMed]

26. Xu, H.; Xu, J.; Jiang, X.; Zhu, Z.; Rao, J.; Yin, J.; Wu, T.; Liu, H.; Liu, S. Thermosensitive Unimolecular Micelles Surface-Decorated with Gold Nanoparticles of Tunable Spatial Distribution. Chem. Mater. 2007, 19, 2489-2494. [CrossRef]

27. Huynh, V.; Ifraimov, N.; Wylie, R.G. Modulating the Thermoresponse of Polymer-Protein Conjugates with Hydrogels for Controlled Release. Polymers 2021, 13, 2772. [CrossRef] [PubMed]

28. Karesoja, M.; Karjalainen, E.; Hietala, H.; Tenhu, H. Phase Separation of Aqueous Poly(2-dimethylaminoethyl methacrylate-blockN-vinylcaprolactams). J. Phys. Chem. B 2014, 118, 10776-10784. [CrossRef]

29. Marsili, L.; Bo, M.D.; Eisele, G.; Donati, I.; Berti, F.; Toffoli, G. Characterization of Thermoresponsive Poly-N-Vinylcaprolactam Polymers for Biological Applications. Polymers 2021, 13, 2639. [CrossRef]

30. Kehrle, J.; Hçhlein, I.M.D.; Yang, Z.; Jochem, A.-R.; Helbich, T.; Kraus, T.; Veinot, J.G.C.; Rieger, B. Thermoresponsive and Photoluminescent Hybrid Silicon Nanoparticles by Surface-Initiated Group Transfer Polymerization of Diethyl Vinylphosphonate. Angew. Chem. Int. Ed. 2014, 53, 12494-12497.

31. Grishkewich, N.; Akhlaghi, S.P.; Yao, Z.; Berry, R.; Tam, K.C. Cellulose nanocrystal-poly(oligo(ethylene glycol) methacrylate) brushes with tunable LCSTs. Carbohydr. Polym. 2016, 144, 215-222. [CrossRef]

32. Moers, C.; Wrazidlo, R.; Natalello, A.; Netz, I.; Mondeshki, M.; Frey, H. (1-Adamantyl) methyl Glycidyl Ether: A Versatile Building Block for Living Polymerization. Macromol. Rapid Commun. 2014, 35, 1075-1080. [CrossRef] [PubMed]

33. Muller, S.S.; Moers, C.; Frey, H. A Challenging Comonomer Pair: Copolymerization of Ethylene Oxide and Glycidyl Methyl Ether to Thermoresponsive Polyethers. Macromolecules 2017, 47, 5490-5500. [CrossRef]

34. Isono, T.; Miyachi, K.; Satoh, Y.; Sato, S.; Kakuchia, T.; Satoh, T. Design and synthesis of thermoresponsive aliphatic polyethers with a tunable phase transition temperature. Polym. Chem. 2017, 8, 5698-5707. [CrossRef]

35. Aoki, S.; Koide, A.; Imabayashi, S.; Watanabe, M. Novel Thermosensitive Polyethers Prepared by Anionic Ring-Opening Polymerization of Glycidyl Ether Derivatives. Chem. Lett. 2002, 32, 1128-1129. [CrossRef]

36. Heinen, S.; Rackow, S.; Schafer, A.; Weinhart, M. A Perfect Match: Fast and Truly Random Copolymerization of Glycidyl Ether Monomers to Thermoresponsive Copolymers. Macromolecules 2016, 50, 44-53. [CrossRef]

37. Ogura, M.; Tokuda, H.; Imabayashi, S.; Watanabe, M. Preparation and Solution Behavior of a Thermoresponsive Diblock Copolymer of Poly(ethyl glycidyl ether) and Poly(ethylene oxide). Langmuir 2007, 23, 9429-9434. [CrossRef]

38. Reinicke, S.; Schmelz, J.; Lapp, A.; Karg, M.; Hellweg, T.; Schmalz, H. Smart hydrogels based on double responsive triblock terpolymers. Soft Matter. 2009, 5, 2648-2657. [CrossRef]

39. Weinhart, M.; Becherer, T.; Haag, R. Switchable, biocompatible surfaces based on glycerol copolymers. Chem. Commun. 2011, 47, 1553-1555. [CrossRef]

40. Becherer, T.; Heinen, S.; Wei, Q.; Haag, R.; Weinhart, M. In-Depth Analysis of Switchable Glycerol Based Polymeric Coatings for Cell Sheet Engineering. Acta Biomater. 2015, 25, 43-55. [CrossRef]

41. Cao, X.; Chen, Y.; Chai, W.; Zhang, W.; Wang, Y.; Fu, P.-F. Thermoresponsive Self-Assembled Nanovesicles Based on Amphiphilic Triblock Copolymers and Their Potential Applications as Smart Drug Release Carriers. J. Appl. Polym. Sci. 2015, $11,41361$. [CrossRef]

42. He, T.; Wang, Y.; Xu, L.; Fu, X.; Narumi, A.; Sato, S.; Shen, X.; Kakuchi, T. Poly[glycidyl oligo(oxyethylene)carbamate $]_{s}\left(\mathrm{PG}_{n}\right.$-EO $_{m} \mathrm{R}^{\prime}$ and $\left.\mathrm{RPG}_{n}-\mathrm{EO}_{m} \mathrm{R}^{\prime}\right)$ : Controlled Synthesis and Effects of Molecular Parameters ( $n$ and $m$ ), Side Group (R'), and End-Group (R) on Thermoresponsive Property. Polym. Chem. 2021, 12, 2580-2591. [CrossRef]

43. Thomas, A.; Müller, S.S.; Frey, H. Beyond Poly(ethylene glycol): Linear Polyglycerol as a Multifunctional Polyether for Biomedical and Pharmaceutical Applications. Boomacromolecules 2014, 15, 1935-1954. [CrossRef] [PubMed] 